\title{
Lunar Surface Mechanical Properties
}

\author{
E. M. Christensen, ${ }^{1}$ S. A. Batterson, ${ }^{2}$ H. E. Benson, ${ }^{3}$ R. Choate, ${ }^{1}$ R. E. \\ Hutton, ${ }^{4}$ L. D. JAFFe, ${ }^{1}$ R. H. Jones, ${ }^{5}$ H. Y. Ko, ${ }^{6}$ F. N. Schmidt, ${ }^{7}$ \\ R. F. Scott, ${ }^{8}$ R. L. SPencer, ${ }^{1}$ and G. H. Sutton ${ }^{9}$
}

\begin{abstract}
The surface material at the Surveyor $\mathbf{5}$ site is granular and slightly cohesive. Spacecraft footpads plowed trenches in this material as the spacecraft slid during landing. For a compressible soil model, a static bearing capacity of 2.7 newtons $/ \mathrm{cm}^{2}$ gave best agreement with the observations. Static firing of the vernier engines against the surface moved surface particles; a crater $20 \mathrm{~cm}$ in diameter and about $1 \mathrm{~cm}$ deep was produced, apparently at engine shutdown. The permeability of the soil to gases, to a depth of about $25 \mathrm{~cm}$, is $1 \times 10^{-8} \mathrm{~cm}^{2}$, corresponding to soil particles mostly 2 to $60 \mu$ in diameter.
\end{abstract}

\section{Spacecraft Landing}

Description. The basic configuration and landing mechanism for Surveyor 5 were essentially the same as for Surveyors 1 and 3. During the landing, the three landing legs rotate upward against the resistance of the shock absorbers. Following the initial impact, the shock absorbers re-extend, returning the legs to their pre-touchdown positions. Additional capability for energy dissipation is provided by crushable footpads and by crushable honeycomb blocks mounted on the underside of the spaceframe, inboard of each leg.

The actual landing of Surveyor 5 can be reconstructed quite accurately from various telemetry signals together with available landingdynamic simulations. Pertinent telemetry data are:

1. Digital indications of spacecraft altitude, three orthogonal velocities, three orthogonal

${ }^{1}$ Jet Propulsion Laboratory, California Institute of Technology, Pasadena, California 91103.

2 Dynamic Loads Division, NASA Langley Research Center, Hampton, Virginia 23361.

3 Manned Spacecraft Center, Houston, Texas 77058.

${ }^{4}$ TRW Systems, Inc., Redondo, California 90278.

5 Hughes Aircraft Co., El Segundo, California 90045.

${ }^{6}$ University of Colorado, Boulder, Colorado 80302.

7 Bellcomm, Washington, D. C. 20036.

8 California Institute of Technology, Pasadena, California 91109.

${ }^{9}$ Hawaii Institute of Geophysics, University of Hawaii, Honolulu, Hawaii 96822. angular positions, one accelerometer reading, and three vernier engine thrust commands.

2. Analog signals monitoring three straingage bridges, one on each landing leg shock absorber, indicating its axial loading.

3. Post-landing television camera coverage of footpads, crushable blocks, and areas on the lunar surface in which these spacecraft members contacted the surface and came to rest.

4. Post-landing attitude determinations based on the position of the planar array antenna, horizon sightings, and star sightings.

An evaluation of the data indicates that, at an altitude of $4.8 \pm 0.7$ meters, all three vernier engines were cut off, resulting in a free-fall period, during which the spacecraft vertical velocity increased to $4.2 \pm 0.4 \mathrm{~m} / \mathrm{sec}$ at the time leg 1 , the first to contact, encountered the lunar surface. After leg 1 contact a sudden pitch motion, away from leg 1 , occurred with a velocity in excess of $13 \mathrm{deg} / \mathrm{sec}$. Legs 2 and 3 contacted the ground almost simultaneously: leg 2 190 msec, and leg 3197 msec after leg 1 impact. A period of spacecraft slide lasting approximately 1.7 sec followed, during which the spacecraft rolled approximately $+5.9^{\circ}$ counterclockwise, as seen from above. Christensen et al. [1967b] give further details of the landing and of the observations and analyses outlined below.

Figure 1 shows the time histories of the axial forces in the landing-gear shock absorbers from before surface contact until after the spacecraft reached its final position. For each leg, the high loading caused by the first impact lasted approximately 0.2 to $0.25 \mathrm{sec}$. This was 

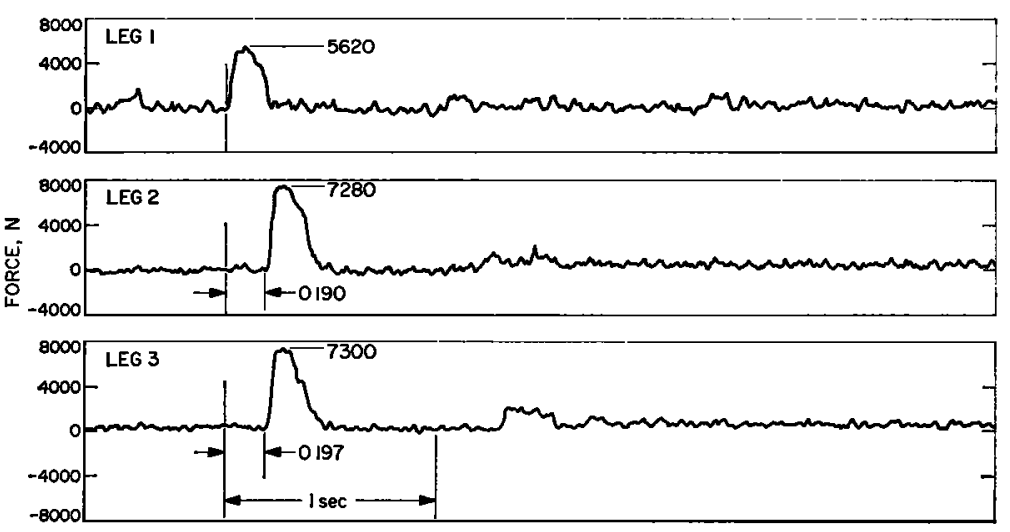

Fig. 1. Strain-gage telemetry data showing shock-absorber axial load histories during landing of Surveyor 5. Maximum forces shown are \pm 350 newtons.

followed by a near-zero force period that lasted approximately 0.6 to $0.8 \mathrm{sec}$, indicating a rebound of the spacecraft caused by the landinggear spring forces. Finally, a second low-energy impact was registered, followed by a poorly defined, low-amplitude oscillation. Similar oscillations, observed during the Surveyor 1 and 3 touchdowns, were related to the combined elastic properties of the spacecraft and the lunar surface [Christensen et al., 1967a, 1968]. After the oscillation, the strain gages indicated a small loading, corresponding to the static loading of the shock absorbers and to the 480 -newton lunar weight of the spacecraft. (1 newton $=10^{5}$ dynes $=0.225 \mathrm{lb} ; 1$ newton $/ \mathrm{cm}^{2}=1.45 \mathrm{lb} / \mathrm{in}^{2}$ )

The final position of the spacecraft, following the slide, is about $19.5^{\circ}$ from vertical.

Television observations of spacecraft-soil interactions. Surveyor 5 landed on the inner slope of a crater, 9 meters wide, about 12

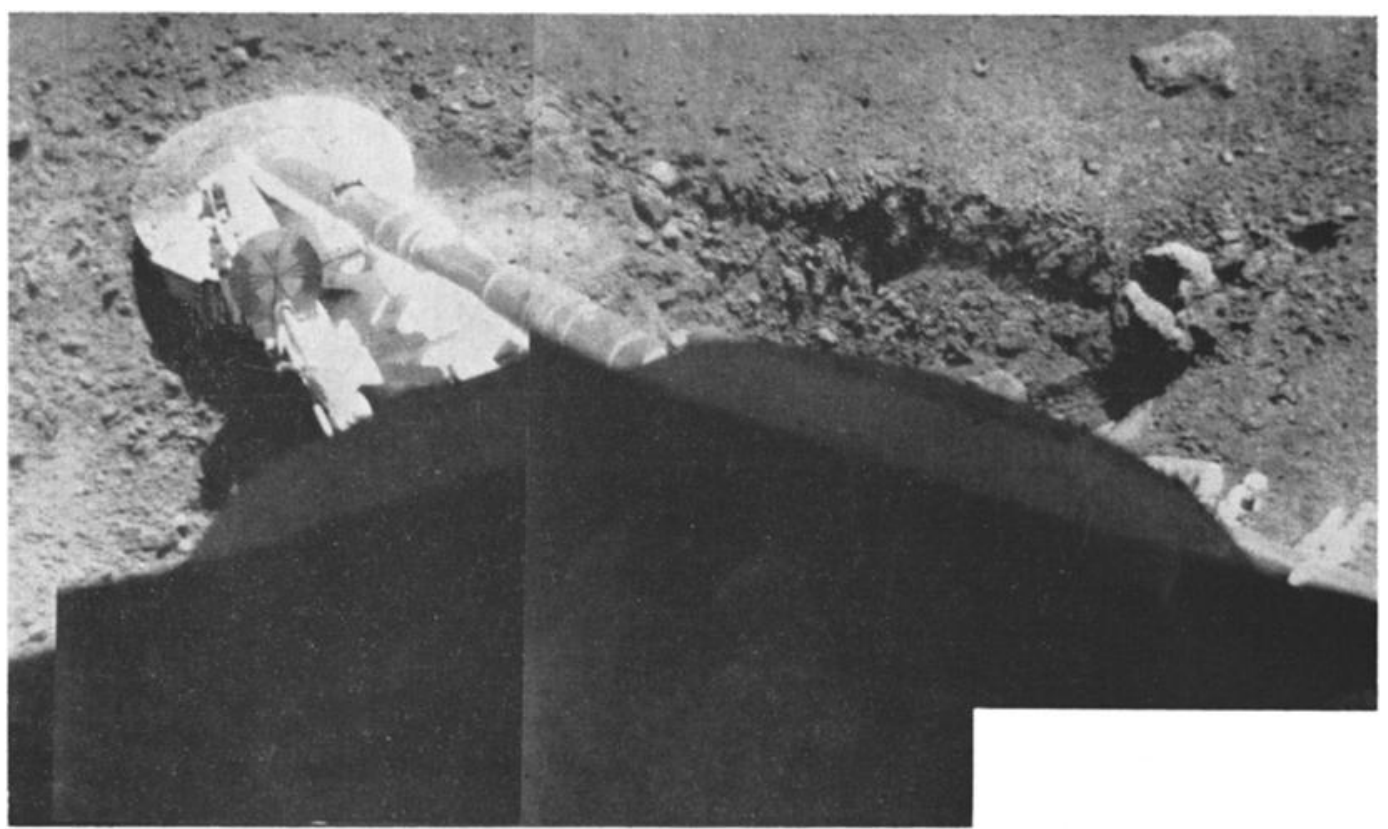

Fig. 2. Wide-angle mosaic of footpad 2 and the trench formed during landing of Surveyor 5. The depression formed during the first impact of footpad 2 can be seen at the right-hand end of the trench. The top of the footpad is $30 \mathrm{~cm}$ in diameter. (Picture taken September 14, 1967, between 04h 00m and 06h 00m GMT; catalog 5-MP-19.) 
meters long, and more than 1 meter deep. After initial touchdown, the spacecraft slid downslope, creating clearly visible surface disturbances. At impact, footpad 2, after possibly grazing a fragment $12 \mathrm{~cm}$ in diameter, penetrated the soil at the right-hand end of the trench shown in Figure 2, forming a depression about $12 \mathrm{~cm}$ deep and ejecting material radially for a distance up to $80 \mathrm{~cm}$. As the spacecraft slid, the outboard rim of footpad 2 tipped downward and the soil in front of it was pushed and thrown forward and sideward, forming the trench, which is 8 to $10 \mathrm{~cm}$ deep at the uphill end, near the impact depression, and 3 to $6 \mathrm{~cm}$ at the downhill end. The ejected material extends approximately $30 \mathrm{~cm}$ beside the trench and 75 $\mathrm{cm}$ beyond the resting position of footpad 2, in the direction of spacecraft slide. The trench is almost straight and its length indicates that the footpad slid $81 \pm 2 \mathrm{~cm}$. The rim of the trench crumbled, partially filling the bottom. The smooth appearance of an area where the footpad scraped along the trench wall shows that the material consists primarily of very small particles.

The movement of footpad 3 also caused some trenching during the landing and subsequent sliding motion. The visibility of this area to the television camera is partially obscured, but it appears that footpad 3 moved approximately the same distance as footpad 2. Like footpad 2, it tipped downward during the trenching, and lunar material was deposited on top of both footpads as they plowed the surface (Figures 2 and 3). No visible soil was deposited on the footpad tops of Surveyors 1 or 3 during landing. Surveyor 5 footpads 2 and 3 are tilted approximately $16^{\circ}$ relative to the plane of the three footpads.

The crushable blocks contacted the lunar surface during the landing. Figure $4 a$ is a narrow-angle view of crushable block 3 in which a small rock or clod appears to be wedged between the block and its thermal shield. In a picture taken later, at a low sun angle, this fragment is no longer visible, but a deposit of

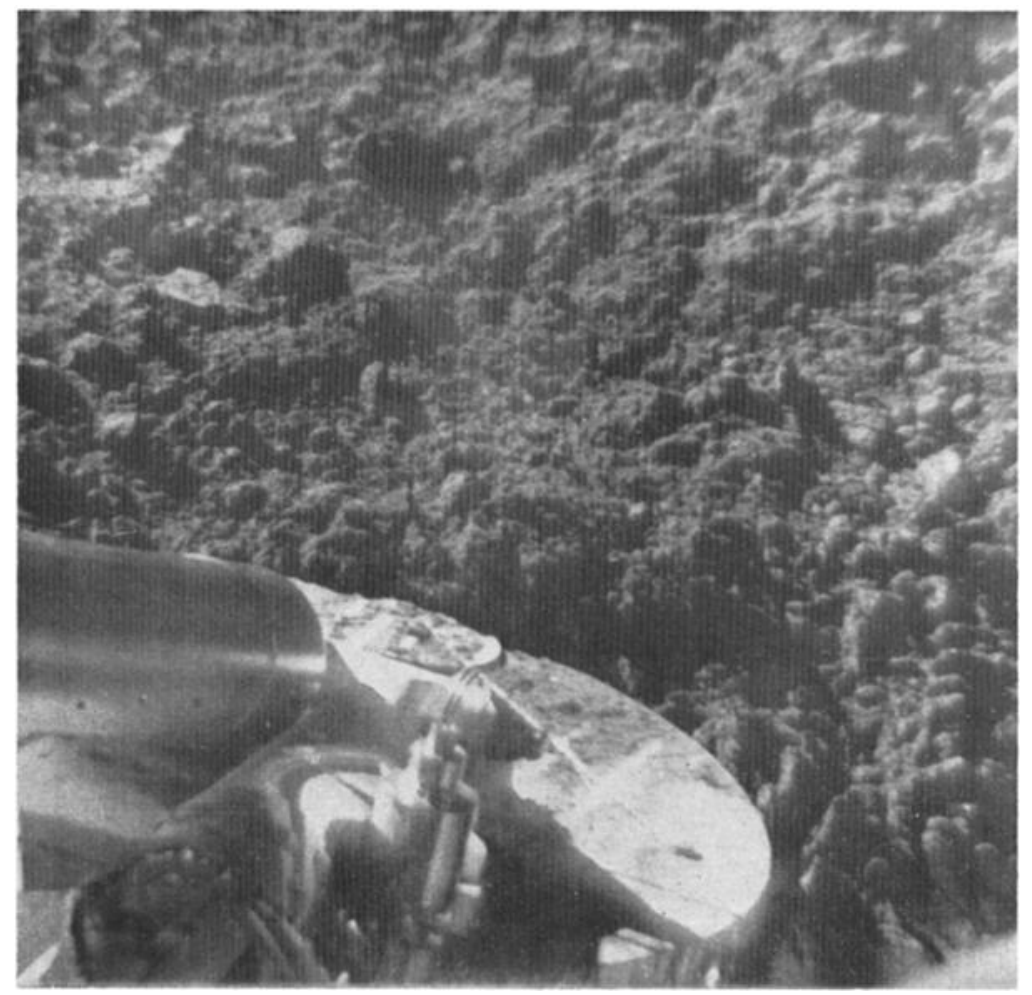

Fig. 3. Narrow-angle picture of top of footpad 3 showing the lunar material on the footpad (September 22, 1967, 13h 48m 13s GMT). 
(a)

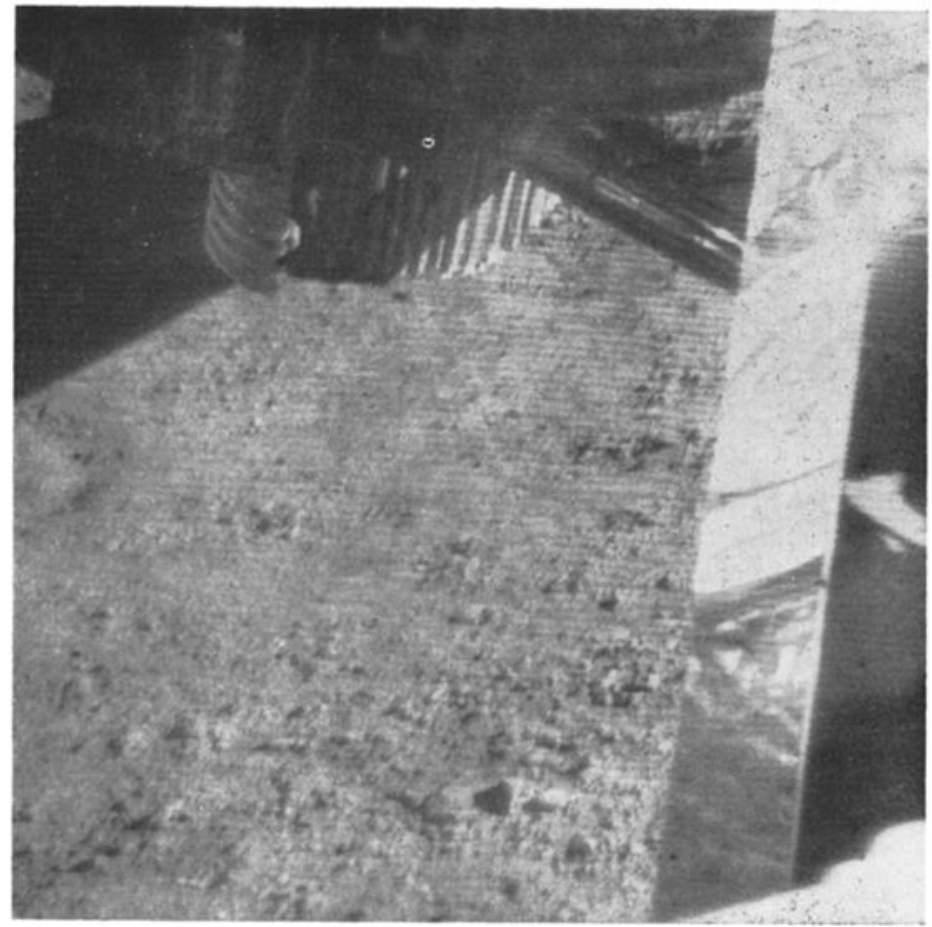

(b)

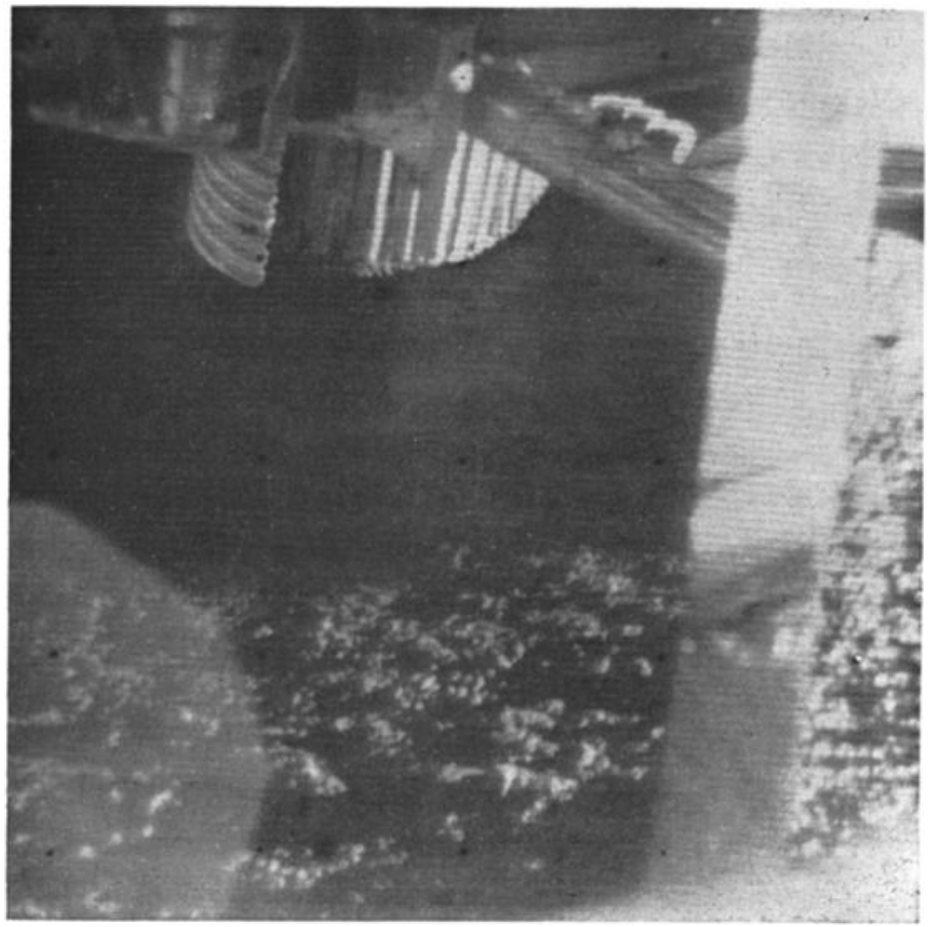

Fig. 4. Narrow-angle view taken through the auxiliary mirrors showing crushable block 3 , with material probably picked up during the first landing impact. (a) Note small rock or clod wedged between the block and the thermal shield (September 20, 1967, 11h 47m 23s GMT). (b) Note lunar material adhering to the bottom of the block (September 23, 1967, 06h 02m 50s GMT). 


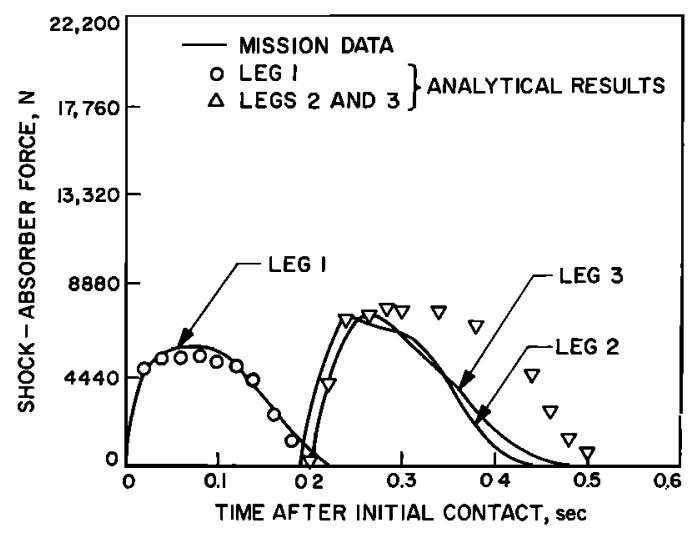

Fig. 5. A comparison of Surveyor 5 landing data with analytically obtained shock-absorber force/time histories.

soil particles can be seen adhering to the bottom edge of the block (Figure $4 b$ ). No clear evidence of crushable block imprints was obtained. However, the probable locations at which crushable block imprints might exist are in areas obscured or shaded by the spacecraft.

The appearance of the lunar surface material at the Surveyor 5 landing site is similar to that in the vicinity of the Surveyor 1 and 3 landing sites [Christensen et al., 1967a, 1968]. The soil is granular, slightly cohesive, and generally finegrained. Some lighter-appearing fragments are seen and presumably are rocks. Darker-appearing fragments are presumed to be soil aggregates, some of natural origin and others produced by the spacecraft landing. The material ejected from the surface by the Surveyor 5 footpads exhibits less brightness contrast with the undisturbed surface than did the soil ejected by Surveyors 1 and 3 .

Dynamic simulations of landing. Computer simulation studies of landings, using several analytical soil models, are being performed to estimate the mechanical properties of a surface material that will display penetrations and shock-absorber axial loads similar to those obtained during the Surveyor 5 landings. The best correlation obtained to date is shown in Figure 5 , which compares the shock-absorber force histories for a simulated landing on a lunar surface with a 2.7 -newtons $/ \mathrm{cm}^{2}$ static bearing strength, with the histories from Surveyor 5 . The penetrations by footpads 1,2 , and 3 obtained in this simulation are 6,12 , and $12 \mathrm{~cm}$, respectively. Because of limited visibility, it is not possible to estimate the initial penetrations of footpads 1 and 3 of Surveyor 5. The analytical simulation indicates that crushable blocks 2 and 3 each penetrated about $8 \mathrm{~cm}$ and that crushable block 1 did not touch the surface.

Because of computer program limitations at this early stage of the dynamic study, the soil model used in this analysis is completely compressible; the force $F$ developed on the footpad is expressed by [Dietrick et al., 1966]

$$
F=p_{0} A(1+c s)+\frac{\rho_{1} \rho_{2}}{\rho_{2}-\rho_{1}} A \dot{s}^{2}
$$

where

$$
\begin{aligned}
p_{0} & =\text { static bearing pressure of surface. } \\
A & =\text { effective footpad area. } \\
c & =\text { frictional constant. } \\
s & =\text { depth of penetration. } \\
\dot{s} & =\text { velocity of penetration. } \\
\rho_{1} & =\text { original density of soil. } \\
\rho_{2} & =\text { density of soil compressed by footpad. }
\end{aligned}
$$

Figure 6 illustrates the soil model being penetrated by a footpad. The surface material initially of density $\rho_{1}$ is compressed at pressure $p_{0}$ to a density $\rho_{2}$ under the penetration of a footpad. Forces resisting penetrations are the static bearing pressure that is assumed constant with depth, friction that increases linearly with penetration, and soil inertia. For the above soil model the assumed relationships between the density of the soil, density of the soil compressed by a footpad, and static bearing pressure are shown in Figure 7. As indicated, for a surface with a bearing strength of 2.7 newtons/ $\mathrm{cm}^{2}$, the assumed density of the undisturbed material would be $1.1 \mathrm{~g} / \mathrm{cm}^{3}$. This value is lower than some estimates derived from previous Surveyor landings and may be changed as the agreement between simulation and actual

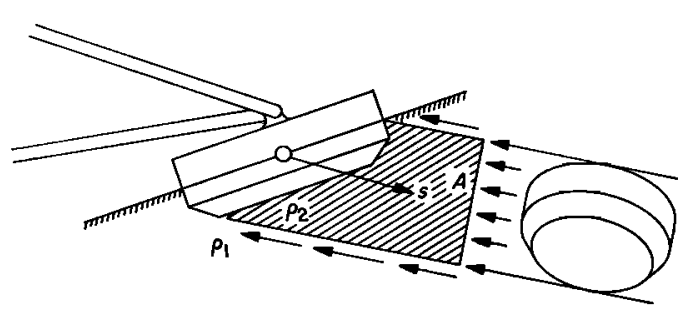

Fig. 6. Soft-surface model for the landing $d y$ namies analysis. 


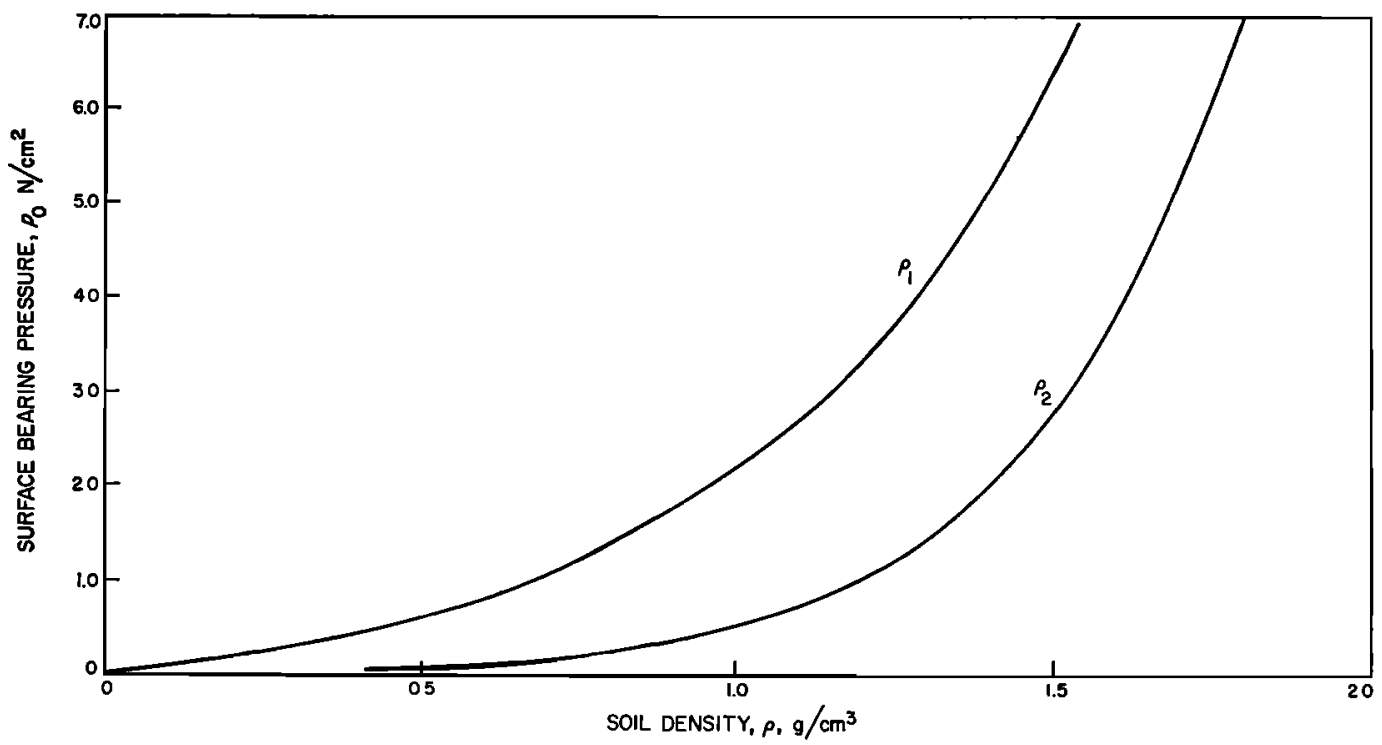

Fig. 7. Assumed relationship between surface bearing pressure and the soil density at the surface.

landing is improved in subsequent solutions. Dynamic analyses using incompressible soil models have not yet been performed for Surveyor 5 .

Simulations of the earlier missions, using the same compressible soil model, showed good correlation with landing data for static bearing pressures of 3.4 newtons $/ \mathrm{cm}^{2}$, rather than the 2.7 newtons $/ \mathrm{cm}^{2}$, which best matches Surveyor 5 data. However, the downslope landing of Surveyor 5 produced a horizontal loading on the soil with a possible deformational mode that would result in greater footpad penetration.

These preliminary results suggest that the lunar surface material at the Surveyor 5 landing site is somewhat weaker than the material at the previous landing sites, or that its resistance is less because of the sloping surface on which the landing took place.

Analysis of spacecraft. Since the spacecraft is at rest on a $20^{\circ}$ slope, the minimum effective coefficient of friction (braking) between the footpads and surface is $\tan 20^{\circ}=0.36$. An analysis of the dynamics of the spacecraft slide by Christensen et al. [1967b] indicates that the average stopping force corresponds to an effective coefficient of friction of 0.73 . These results are, however, of limited value because the footpads penetrated the surface. There were obvious significant variations in the trenching and in the normal force of the footpads against the lunar surface, as indicated by the strain gages and trench depths. Perhaps a more meaningful value is the average stopping pressure supplied by the soil against the footpads. Estimating an average depth of penetration of 5 $\mathrm{cm}$, this pressure is 0.9 newtons $/ \mathrm{cm}^{2}$. This value is consistent with the stalling pressure observed during the Surveyor 3 lunar trenching operations using the soil mechanics surface sampler [Scott and Roberson, 1968].

Lunar Sorc Erosion Test-Observed Effects

To provide data for estimating the amount of soil erosion during a landing of the Apollo Lunar Module (LM) and to determine such lunar surface properties as permeability to gases, cohesion, and particle size, the Surveyor 5 liquid-propellant vernier engines were fired against the lunar surface for $0.55 \pm 0.05$ sec on September 13, 1967, at 05h 38m GMT. Engines 1 and 3 fired at a $120 \pm 22$-newton thrust level, and vernier engine 2 fired at a $76 \pm 18$ newton thrust level. During the firing, the spacecraft footpads remained in place on the lunar surface.

The effects of the vernier engine firing were observed by comparing television pictures obtained before and after the firing. The location and relationship of the Surveyor 5 vernier en- 
gines and television camera to the areas where erosion effects were detected and to other spacecraft components are shown in Figure 8 . The erosion caused by vernier engine 3 provided the primary erosion experimental data. The area under vernier engine 1 was partially visible.

Lunar surface below vernier engine 3. Changes in the lunar surface caused by erosion can be seen in Figures 9 and 10 in the areas labeled $\mathrm{E}_{3 \mathrm{M}}$ and $\mathrm{E}_{\mathrm{sD}}$ in Figure 8. It is evident that there has been:

1. Erosion of soil from area $E_{3 M}$; most soil fragments identifiable in Figure 9 were moved by the firing.

2. Formation of a shallow crescent-shaped crater directly below vernier engine 3 . The crater is $20 \mathrm{~cm}$ in diameter and 0.8 to $1.3 \mathrm{~cm}$ deep; its open end points approximately toward the sensor head of the $\alpha$-scattering instrument. Figure 11 is a contour map of the crater and profiles across it.
Area around $\alpha$-scattering sensor head. The surface area immediately adjacent to the $\alpha$ scattering instrument shows most clearly the extent and amount of soil disturbance caused by the vernier engine firing. Figures $12 a$ and $12 b$ are controlled mosaics composed of narrow-angle, pre- and post-firing pictures of the area $\left(A_{v 3}\right.$ in Figure 8$)$. A comparison indicates that the firing caused a number of changes, including movement of the $\alpha$-scattering instrument sensor head, movements of rock and soil fragments, and alteration to general surface features.

In places the basic soil surface has been changed by the firing. Clear evidence of this is shown by the track, about $2 \mathrm{~mm}$ deep and 58 $\mathrm{cm}$ long, indicated by the dotted line in the prefiring picture (Figure 12a); fragment $\mathrm{h}$, probably ejected during the landing, made the track as it rolled downhill. In Figure $12 b$, this track no longer exists, having been filled in or eroded

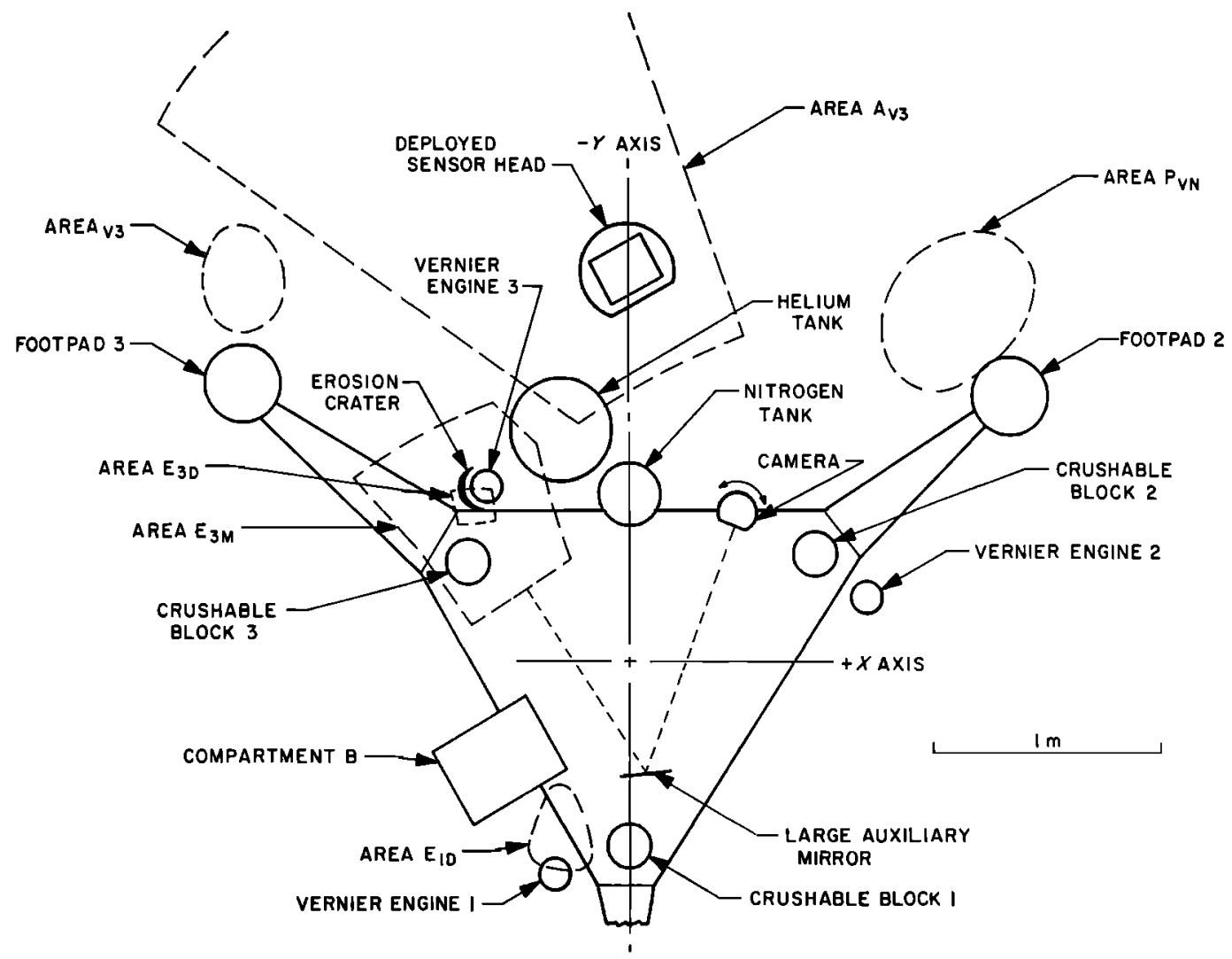

Fig. 8. Drawing showing the relationship of the spacecraft to lunar surface areas affected by the vernier engine firing and viewed by camera. 


\section{(a)}
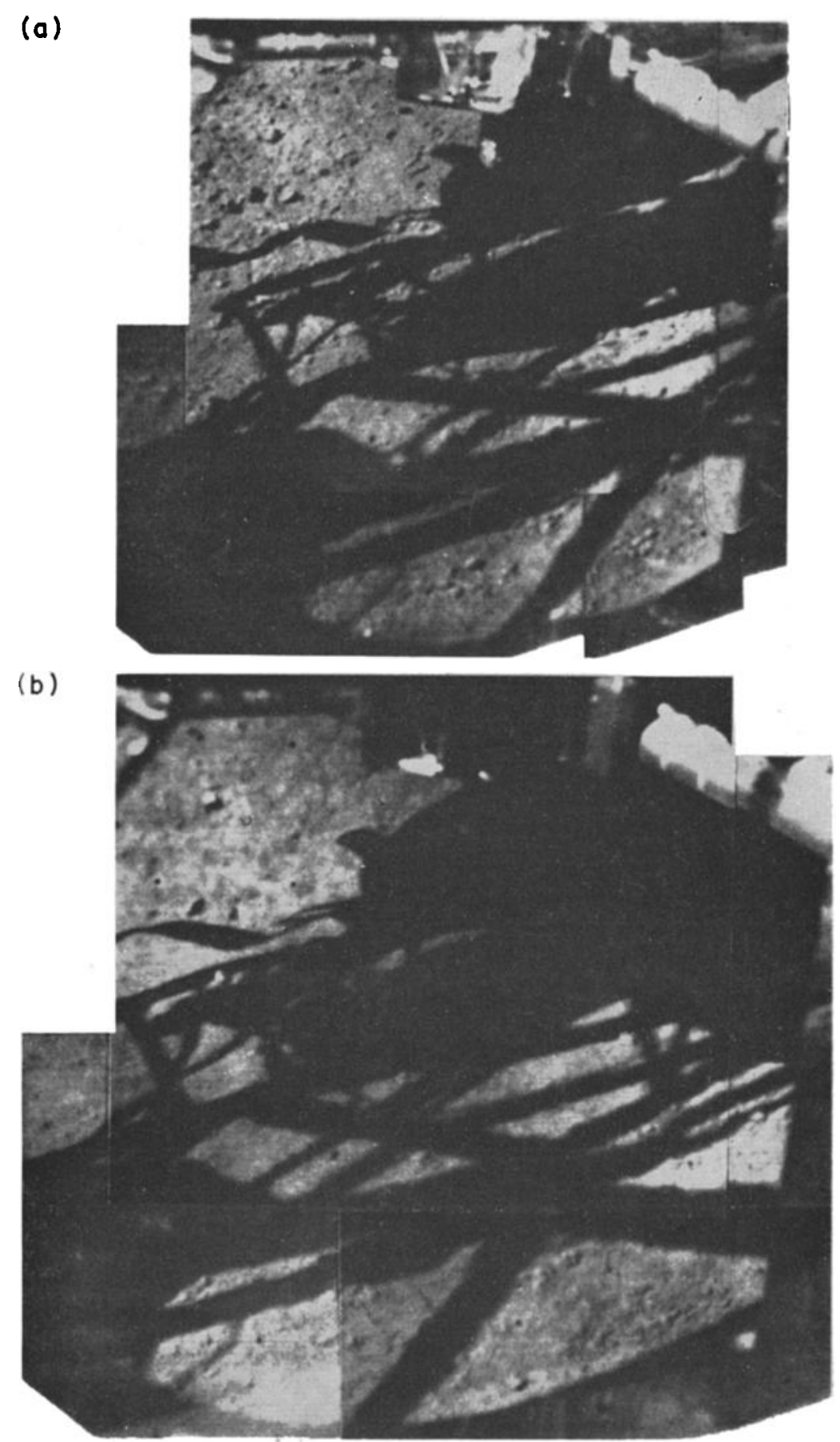

away by the firing. Another example is the material to the right of the helium tank, ejecta deposited during the landing, which is not visible after the firing. Although the ejecta could have been covered or swept away by the firing, evidence suggests the latter. For example, in area $\mathrm{Z}$, some soil around fragment $\mathrm{g}$ and partly covering rock a was definitely swept away, since rock $a$ is exposed to a somewhat greater depth after the firing (Figure 13). For this area, 40 


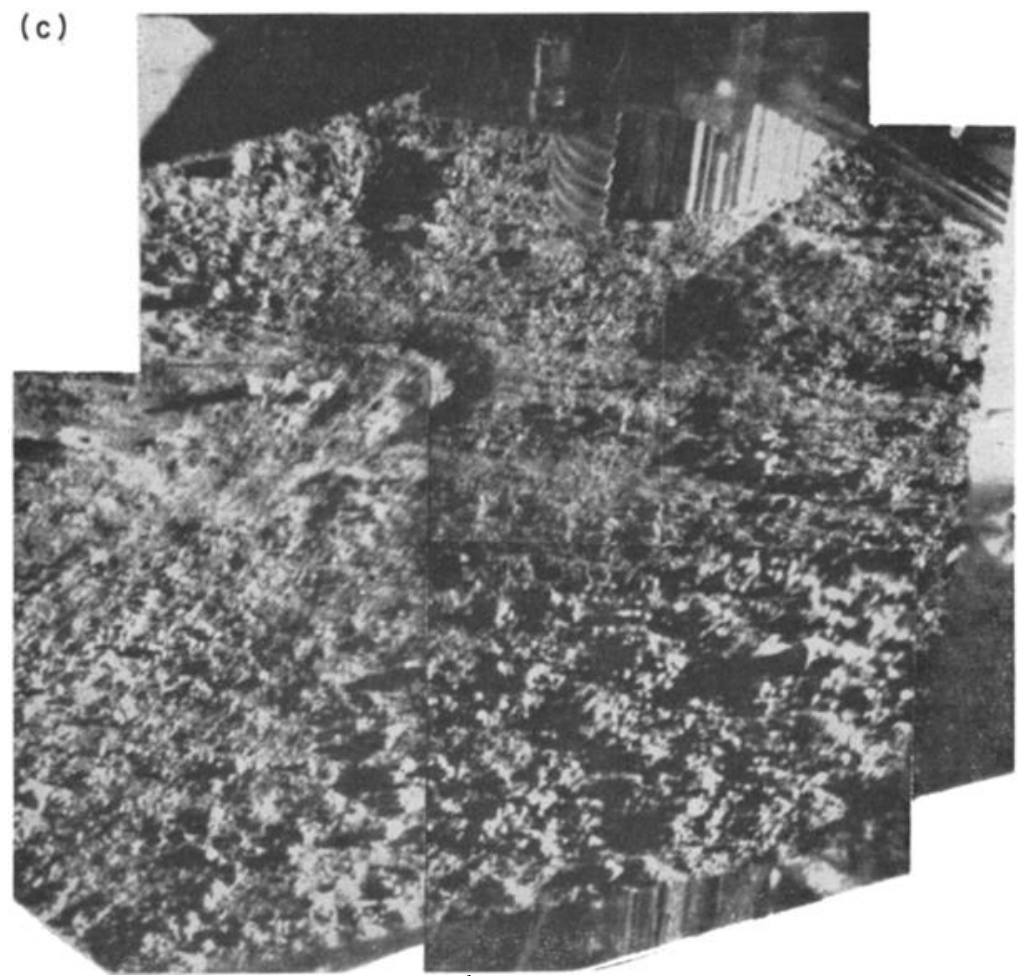

Fig. 9. Narrow-angle mosaics of the lunar surface beneath vernier engine 3, as seen through the auxiliary mirrors, before $(a)$ and after $(b, c)$ on-surface firing. Part of the spacecraft frame and one crushable block are visible at the top of the picture. (a) September 13, 1967, $01 \mathrm{~h} 15 \mathrm{~m}$ 37s GMT; catalog 5-MP-17. (b) September 13, 1967, 07h 33m 40s GMT; catalog 5-MP-18. (c) September 22, 1967, 14h 08m 49s GMT; catalog 5-MP-22.

to $60 \mathrm{~cm}$ from vernier engine 3 , the estimated depth of deposition, erosion, or soil replacement is $1 \mathrm{~cm}$ or more. Soil movement was probably aided by the $20^{\circ}$ surface slope.

None of the fragments that moved can be positively identified in both the pre- and the post-firing mosaics. In some cases, this could be due to movement of particles into the area from locations not in the pre-firing mosaic, or, in other cases, particles shown in the pre-firing mosaic could have moved out of the area during the firing. It is also possible that some of the fragments appear, but, because of the movement and their irregular shape, they present different distinguishing features to the camera, or broke apart, and therefore cannot be identified as the same fragment. Fragments a through $f$ did not move and therefore appear in both Figures $12 a$ and $12 b$. In general, these are the larger fragments; many appear to be partly buried. Figure 14 is a plot of fragment diameter versus pre-firing distance from vernier engine 3 , for some of the larger fragments, showing which moved during the firing and which did not. The circles plotted in this figure indicate fragments that probably were lying on the surface and not partly buried prior to firing. The figure indicates a size-distance boundary below which a fragment could have been moved by the firing.

The $\alpha$-scattering sensor head was displaced by the vernier engine 3 firing. In Figure 12b, points $A$ and $B$ are the pre-firing positions of corners $A^{1}$ and $B^{1}$ of the sensor head.

In Figure 15a (pre-firing), the image of the sensor head circular plate is clearly reflected by the gold-plated front of face D. After the firing (Figure 15b), no reflected image of the plate can be seen. The entire surface of $D$ appears to be nonreflective, with the bottom $3 \mathrm{~cm}$ appear- 
(a)

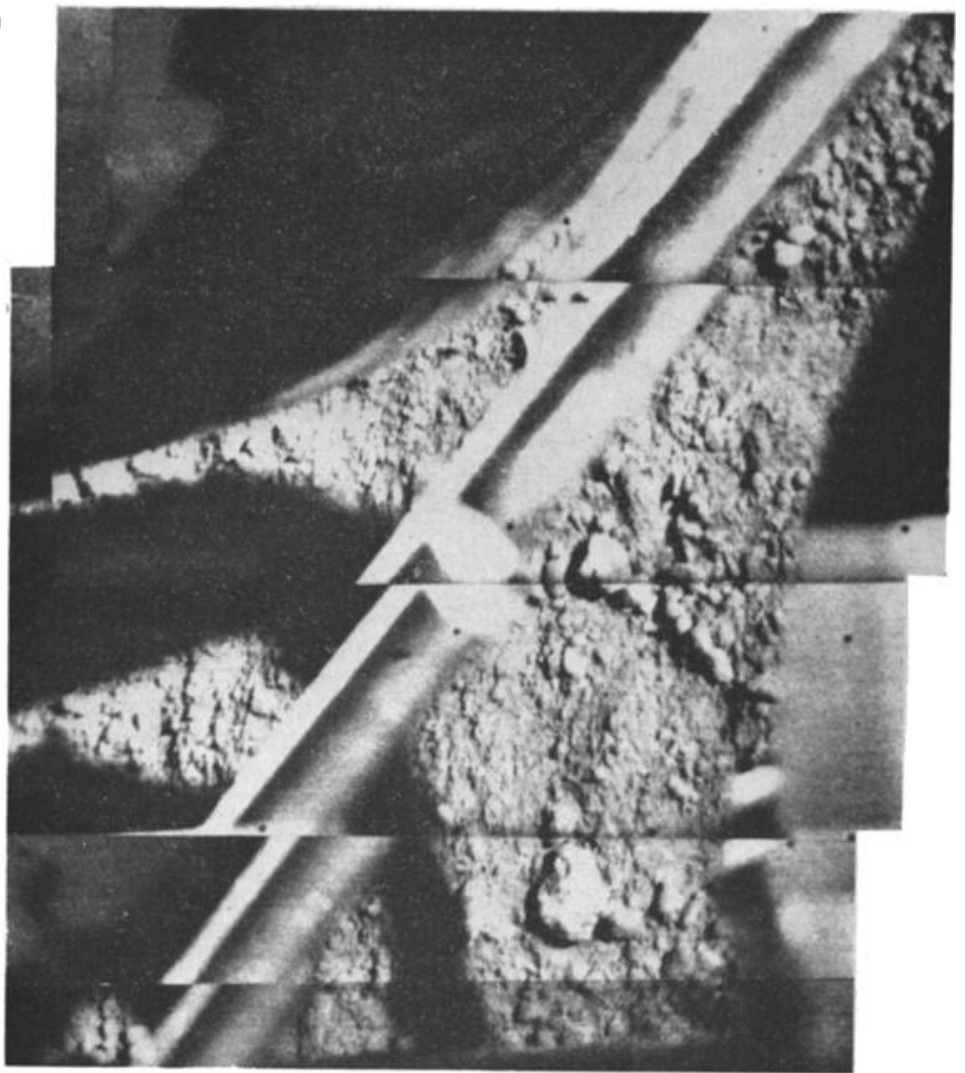

(b)

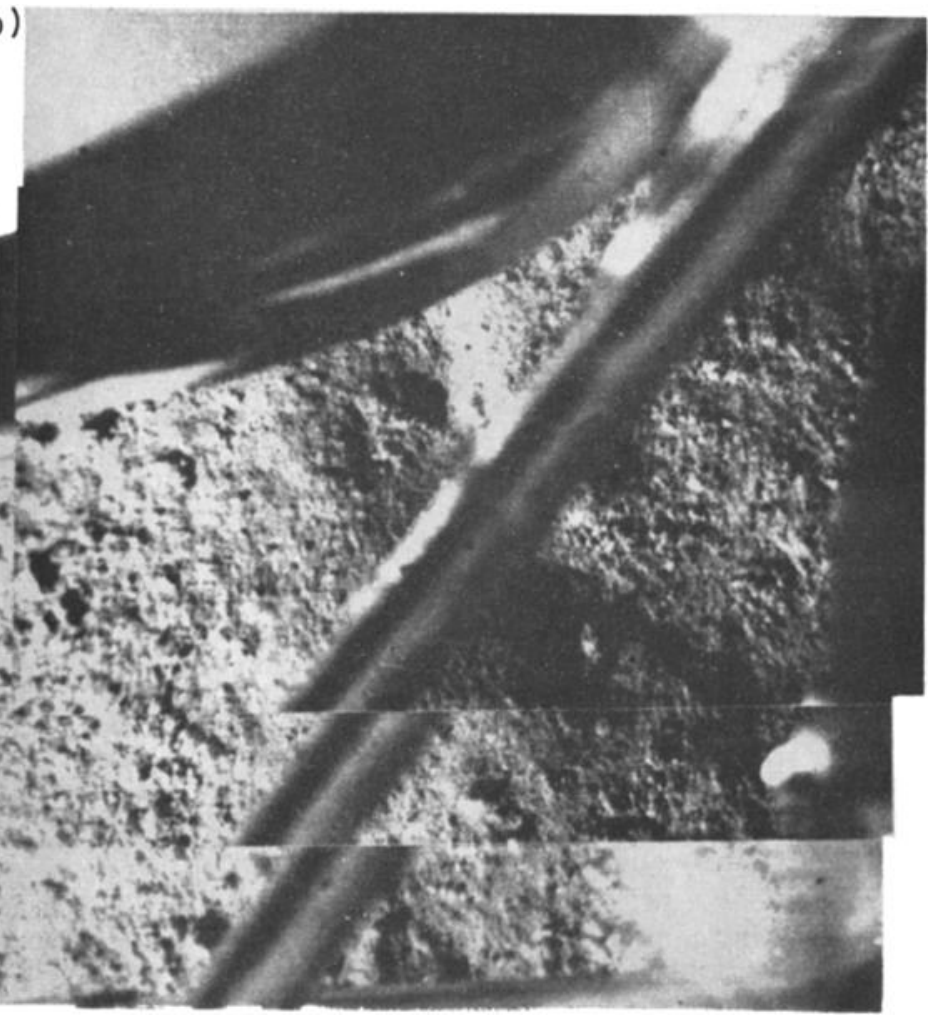




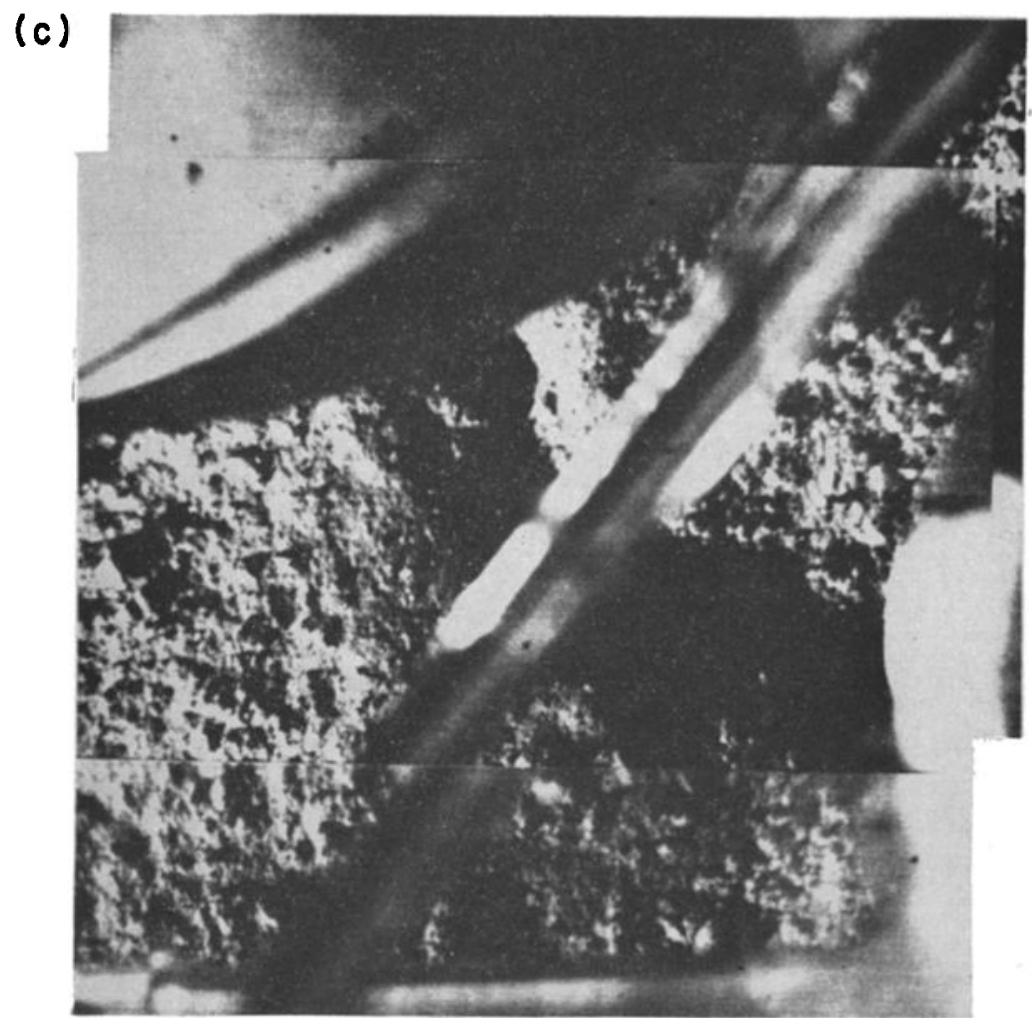

Fig. 10. Narrow-angle mosaics of the lunar surface beneath vernier engine 3, before $(a)$ and and after $(b, c)$ on-surface firing. Two spacecraft tanks and the electronics box on the bottom bound the pictures. A spacecraft structural member divides the visible lunar surface. (a) September 12, 1967, 00h 58m 58s GMT; catalog 5-MP-37. (b) September 21, 1967, 05h 36m 31s GMT; catalog 5-MP-40. (c) September 22, 1967, 13h 36m 49s GMT; catalog 5-MP-42.

ing darker than the top $10 \mathrm{~cm}$. This change is probably caused by the adherence of fine lunar material. Erosion debris covers the intersection of face $D$ and the plate. Fragments and soil appear to have landed on and near the plate after the sensor head stopped sliding when the leading edge of the plate dug into the soil (Figures $15 b$ and $12 b$ ).

Footpad 3 area. A fragment-by-fragment study of the footpad 3 area was made by comparing individual pre- and post-firing pictures using a blink technique. None of the numerous soil fragments outboard of footpad 3 were found to be displaced by the firing. This area is, however, at least partly shielded from the direct blast of vernier engine 3 by footpad 3 and its leg. The soil to the right of the footpad is not shielded from vernier engine 3 , and many of the fragments here were swept away by the firing. The area is 120 to $130 \mathrm{~cm}$ from the engine center line; the largest fragment displaced was $2.0 \mathrm{~cm}$ in diameter.

Footpad $\mathscr{2}$ area. In the footpad 2 area, fragments that can be seen to have moved are entirely limited to the lower-left quarter of Figure 16. Though only a relatively few fragments of 1-cm diameter or larger have been displaced, the fine soil between the larger fragments in the area to the left of footpad 2 was disturbed by the firing. Soil was blown off the magnet bracket and control bar on the left of the footpad.

Footpad 2 trench area. Frame-by-frame comparison of the footpad 2 trench, using a blink technique, shows no visible change caused by static vernier firing. Distance along the ground from the center line of vernier engine 2 to the trench ranges from 90 to $115 \mathrm{~cm}$. 


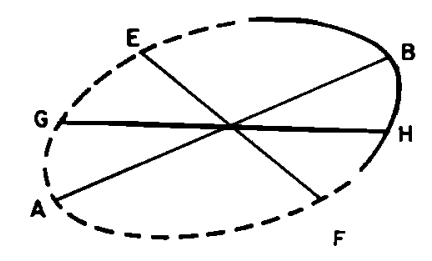

(a) ORIENTATION OF CRATER AS SEEN THROUGH MIRROR BY TV CAMERA

$\sqrt[0]{-1}$

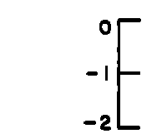

\begin{tabular}{cc}
$E$ & 0 \\
\hline & -1
\end{tabular}

I

$\stackrel{a}{\omega}$

$\underset{-2}{0}$

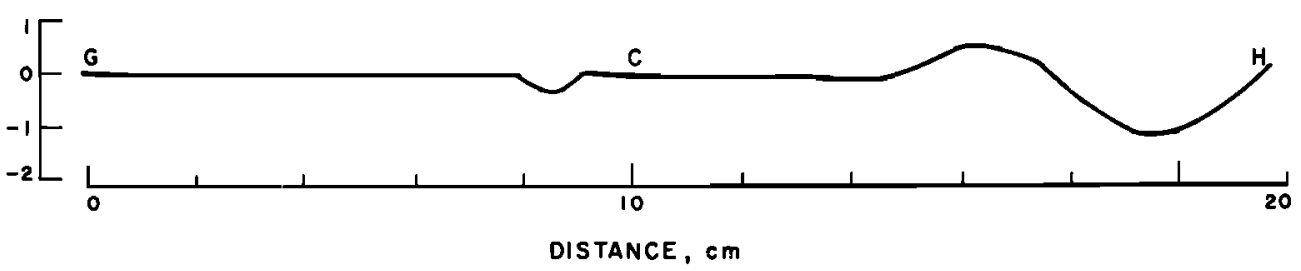

(c) PROFILES ACROSS CRATER

Fig. 11. Plan view and profiles of the crescent-shaped crater produced by the vernier engine 3 firing (taken from a drawing by the Mapping Science Branch, Lunar and Earth Science Division, NASA Manned Spacecraft Center).

(b) PLAN VIEW OF CRATER
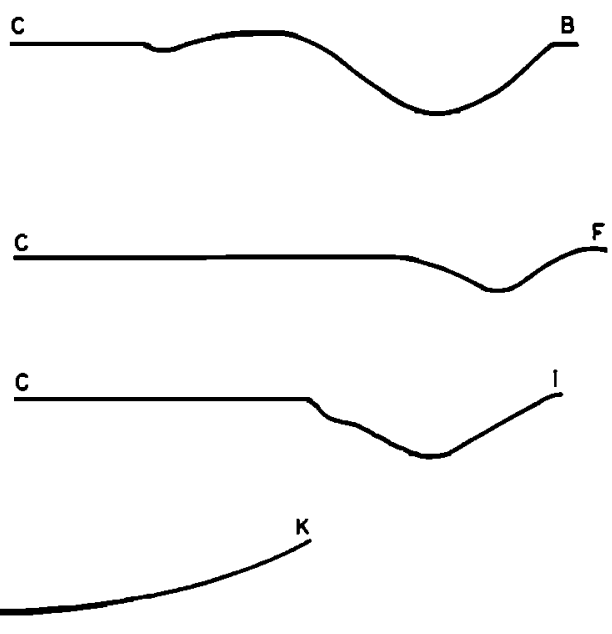
0

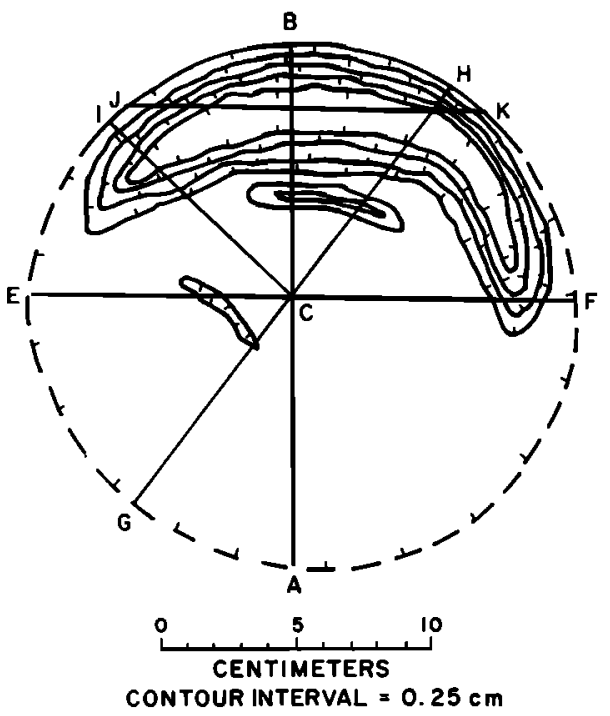




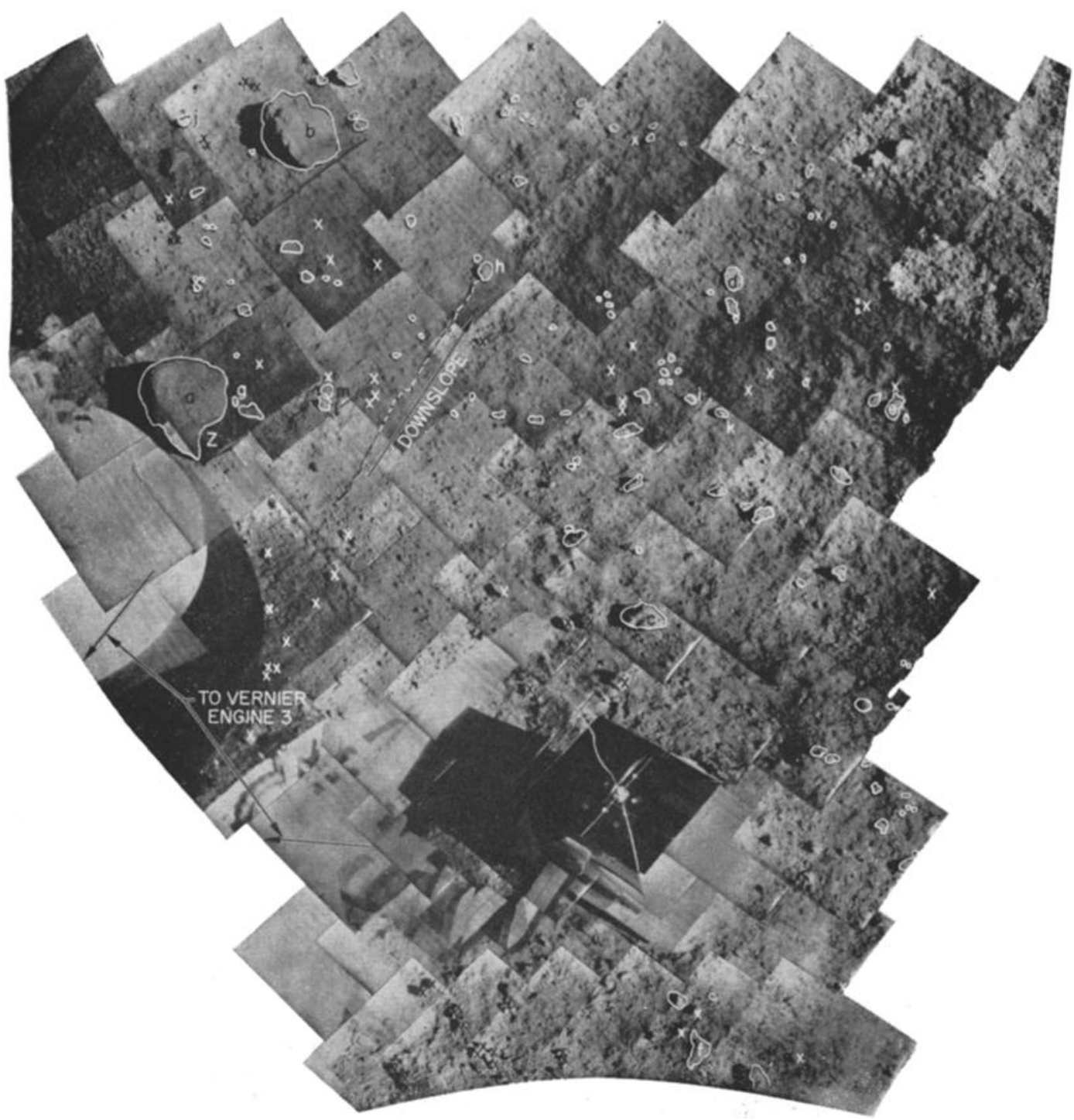

Fig. $12 a$.

Electronic compartment tops. An indication of erosion by diffused gas eruption was obtained by comparing pre- and post-firing pictures of the compartment B top (Figure 17). In Figure $17 b$, clumps of soil, which landed on the compartment top and broke, are visible. Some of the small fragments appear to have rolled downslope or splattered in the plane of the trajectory. The relationship of compartment $\mathbf{B}$ to vernier engine 1 is shown in Figure 8; the top of the compartment was 1.1 meters above the lunar surface. The particles must have had a near-vertical trajectory to reach the top of compartment $B$ from the area under vernier engine 1. There were no noticeable changes in spacecraft temperatures, although the thermal characteristics of the electronic compartment top would have been significantly modified even by a thin layer of soil.

\section{Lunar Soil Erosion Test- Stmulations and ANalysis}

For vernier engine 3 static firing, Table 1 gives the engine parameters, the position of the 


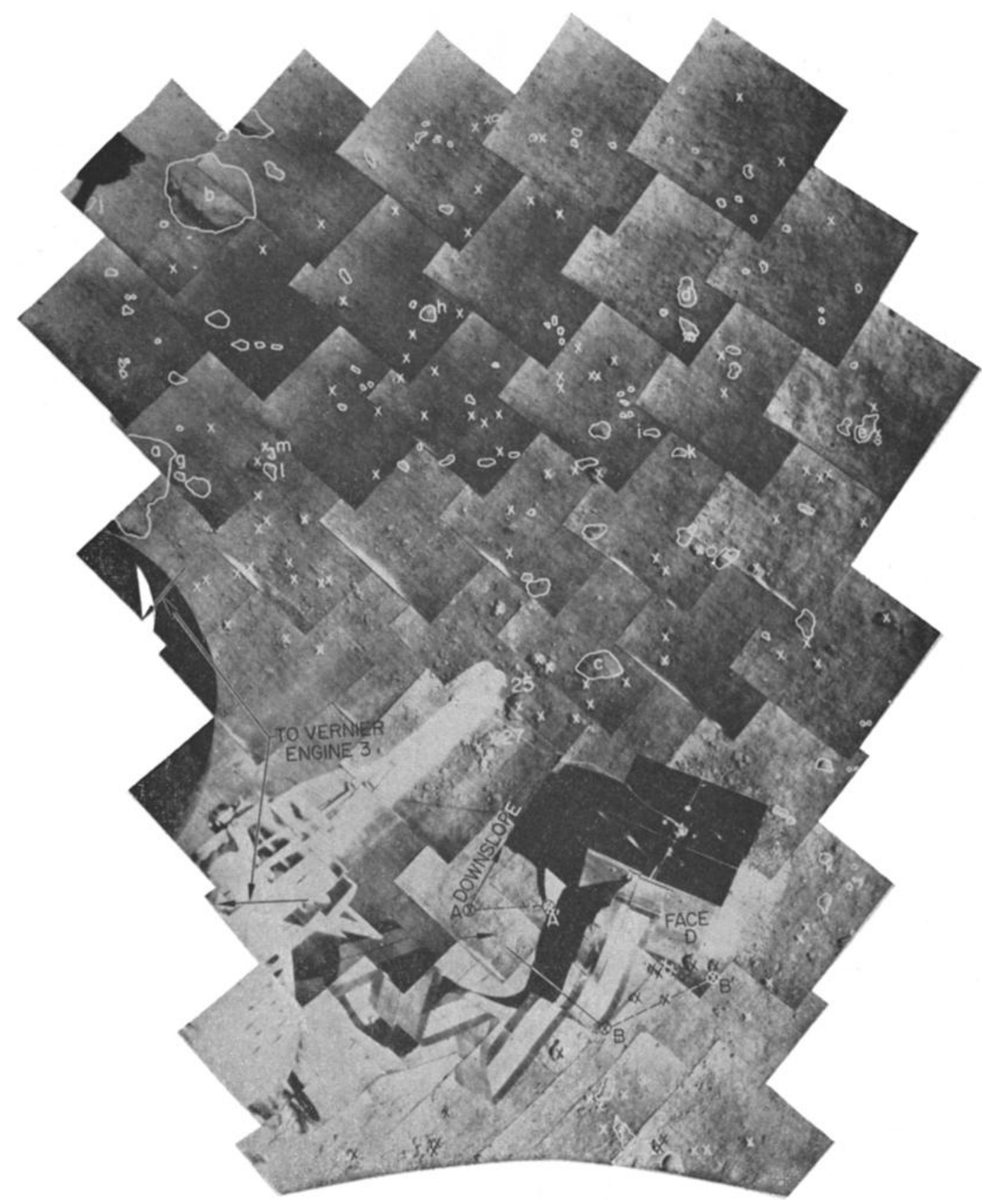

Fig. $12 b$.

Figure 12 shows an annotated mosaic of lunar surface near $\alpha$-scattering instrument $(a)$ before firing and $(b)$ after firing. Rock and soil fragments that were not moved by the firing are outlined; some are labeled by letter. Fragments that were moved are marked with an $\mathrm{x}$; some are labeled by number. The top of the $\alpha$-scattering sensor head is $17 \mathrm{~cm}$ on a side. September 12 and 14, 1967; catalog 5-MP-24 and 5-MP-24). 

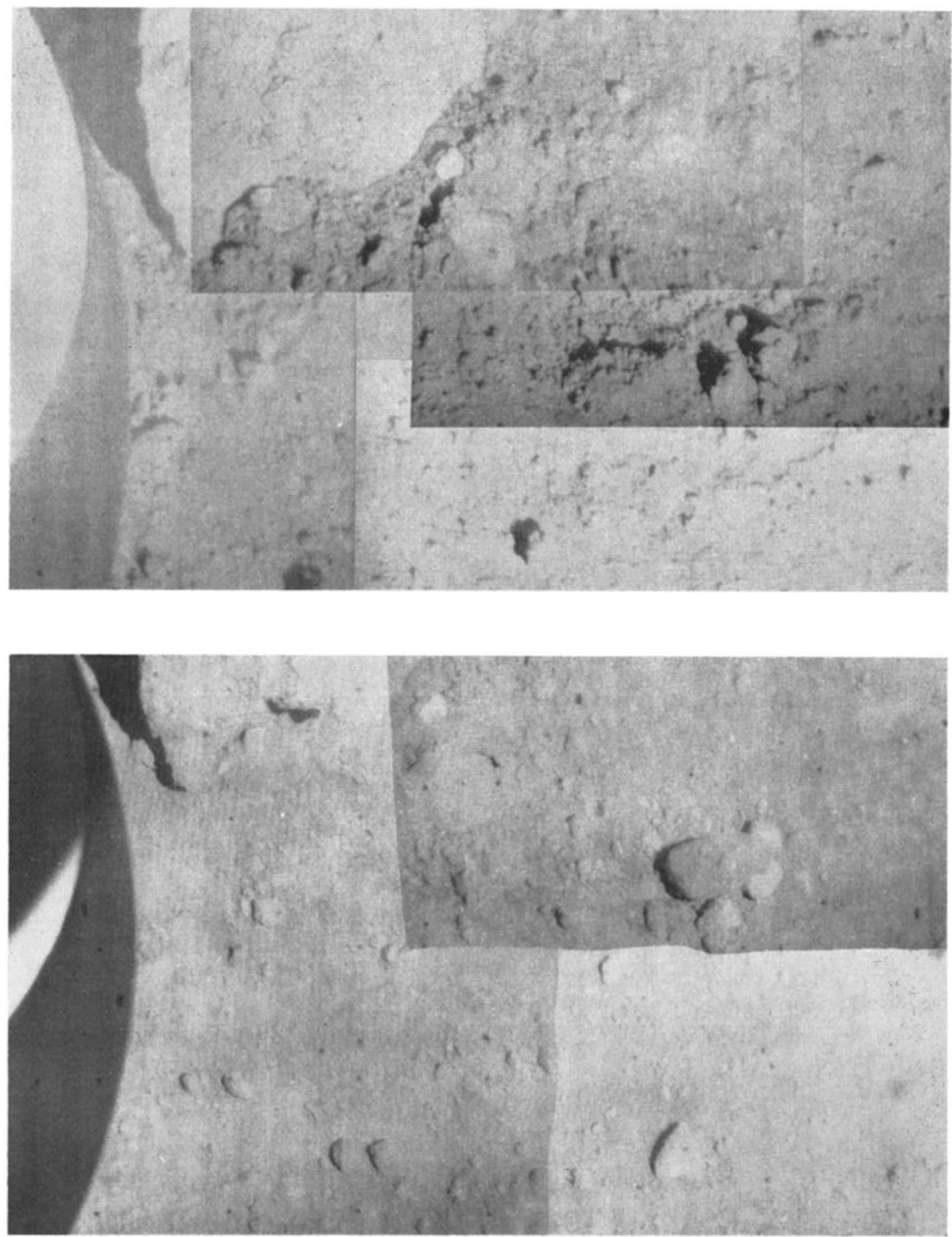

Fig. 13. Lunar surface beside the helium tank (see Figure 12). Soil erosion from around rock a and the trail left by impact of fragment 26 were caused by the firing. (Top) Pre-firing picture (September 12, 1967; catalog 5-MP-45B). (Bottom) Post-firing picture (September 14, 1967; catalog 5-MP-46B). 


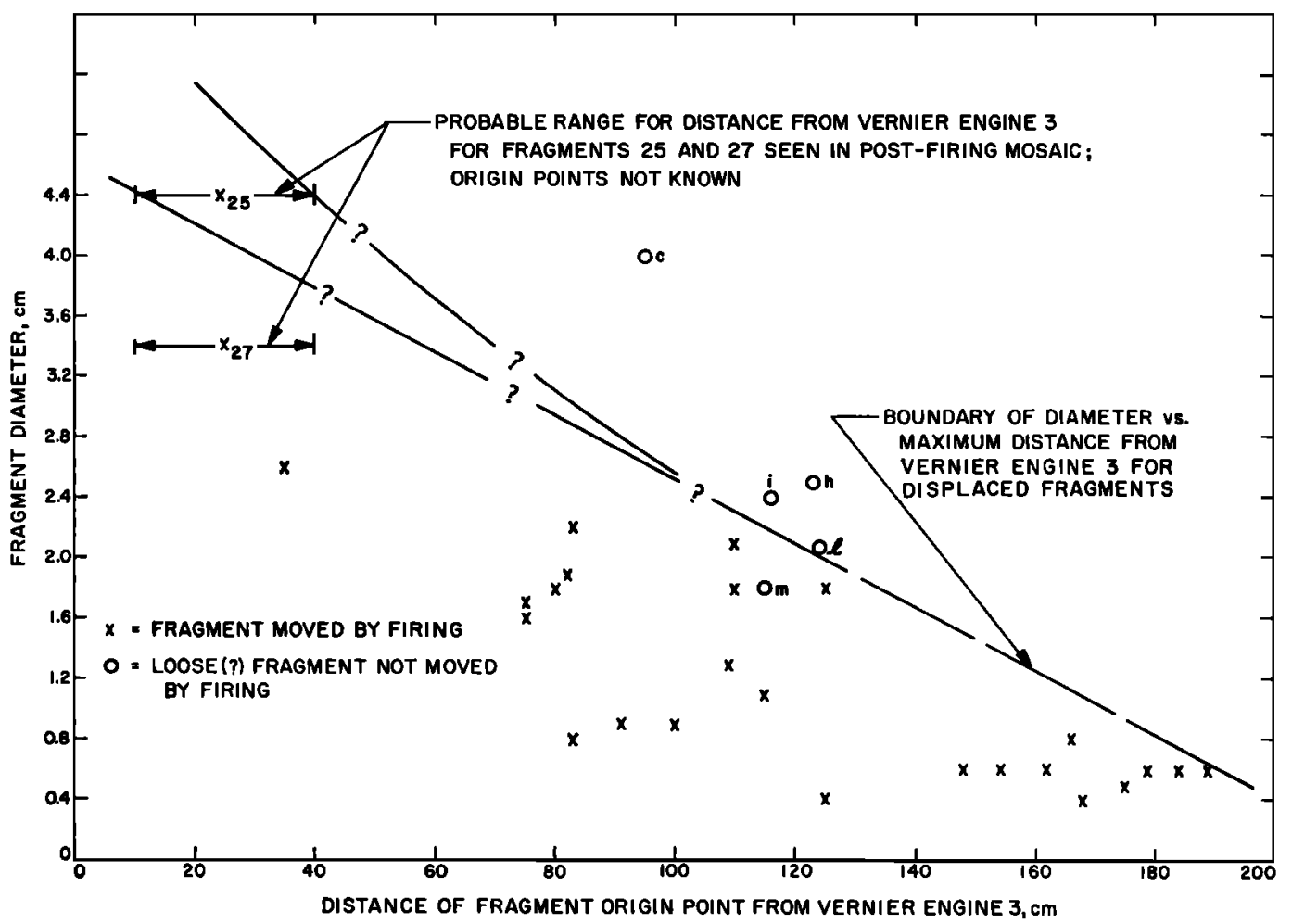

Fig. 14. Graph of diameter versus distance for fragments moved by the firing. The dashed line represents the probable maximum sizes for fragments that could be moved by the firing.

engine relative to the lunar surface below it, and the dimensions of the erosion crater formed. Figure 18 shows the theoretical surface pressure, gas radial velocity, and the corresponding dynamic pressure, as derived from Roberts' [1963, 1964] theory. These data correspond to conditions under which the engine is exhausting onto a flat plane parallel with the nozzle exit plane. For surfaces tilted $0^{\circ}, 10^{\circ}$, and $20^{\circ}$ from the nozzle exit plane at a radial distance of $76 \mathrm{~cm}$, for example, along the projection of the exhaust vector, the theoretical surface pressures are about 14, 76, and 210 dynes $/ \mathrm{cm}^{2}$, respectively. The dynamic pressures vary similarly with tilt.

Soil erosion caused by rocket engine exhaust gas impingment is of three basic types.

1. Bearing load cratering [Alexander et al., 1966]: rapid cratering caused by exhaust gas pressure on a soil surface exceeding the bearing capacity of the surface.

2. Viscous erosion [Roberts, 1963]: erosion by entrainment of soil particles as the gas flows over the surface.

3. Diffused gas eruption [Dodge, 1966; Scott and Ko, 1968]: movement of the soil caused by the upward flow of gas through the pores of the soil during and after the firing.

These three types will be considered separately.

Bearing load cratering. The bearing pressure produced on the lunar surface by engine exhaust was less than 0.3 newton $/ \mathrm{cm}^{2}$ (Figure 18); bearing load cratering, therefore, is considered unlikely, and no evidence of such cratering was observed. (Alexander et al. [1966] call this type of erosion 'explosive cratering.')

Viscous erosion. When a soil is subjected to rocket engine exhaust, the gas that flows radially along the surface may dislodge soil particles from the surface and entrain them. The erosion characteristics of a bed of particles under vacuum conditions $\left(10^{-4}\right.$ torr $)$ were investigated by Land and Clark [1965] for various particle 
(a)

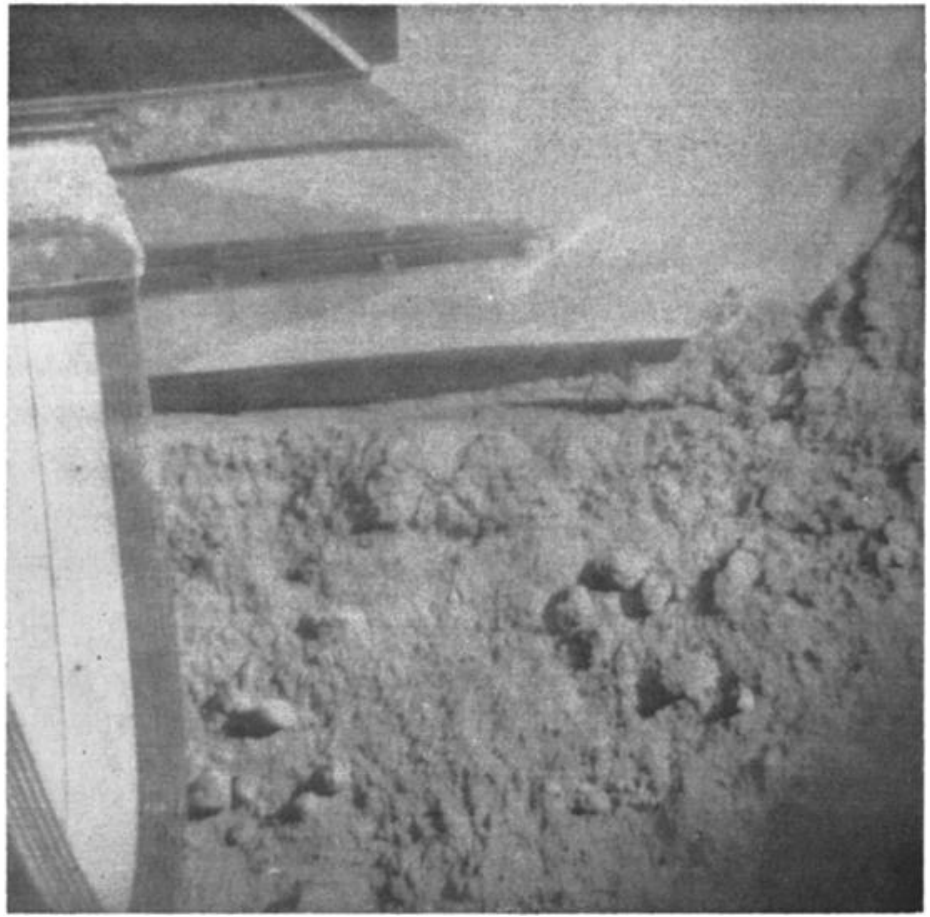

(b)

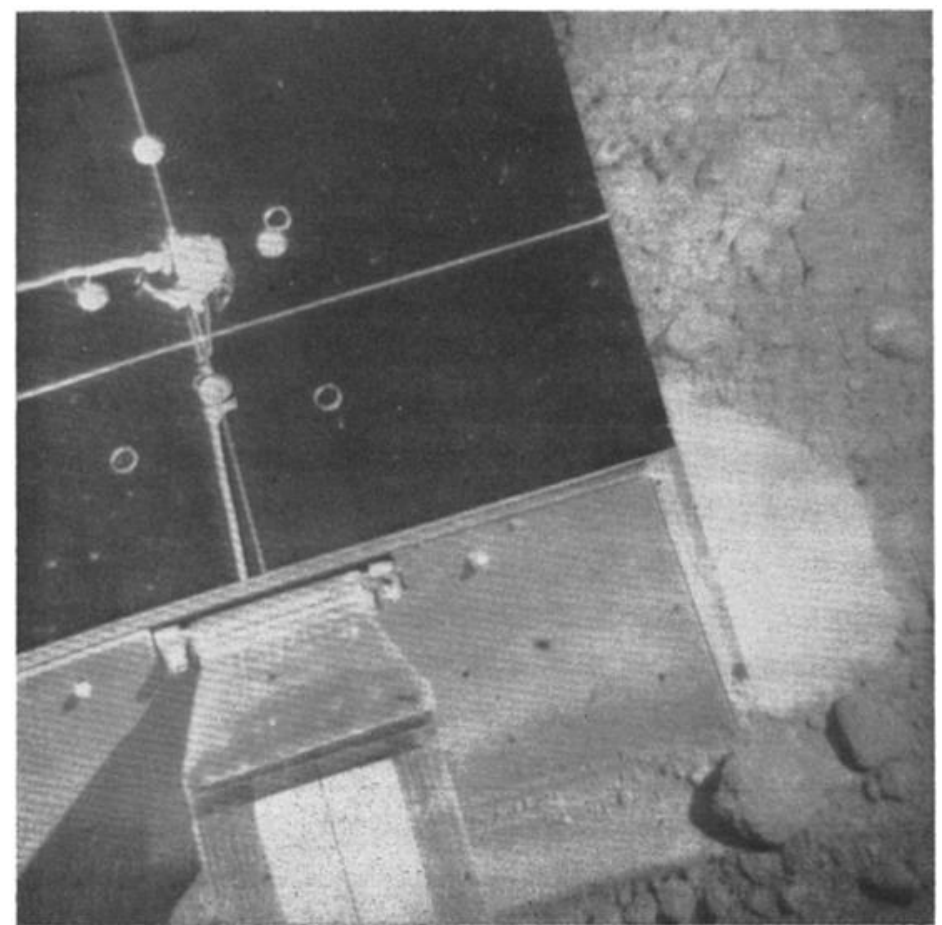

Fig. 15. Gold-plated face D (see Figure 12) of the $\alpha$-scattering sensor head. (Top) Prefiring picture; face D is highly reflective (September 12, 1967, 05h 06m 27s GMT). (Bottom) Post-firing picture; face $D$ is nonreflective (September 14, 1967, 07h 15m 09s GMT). 


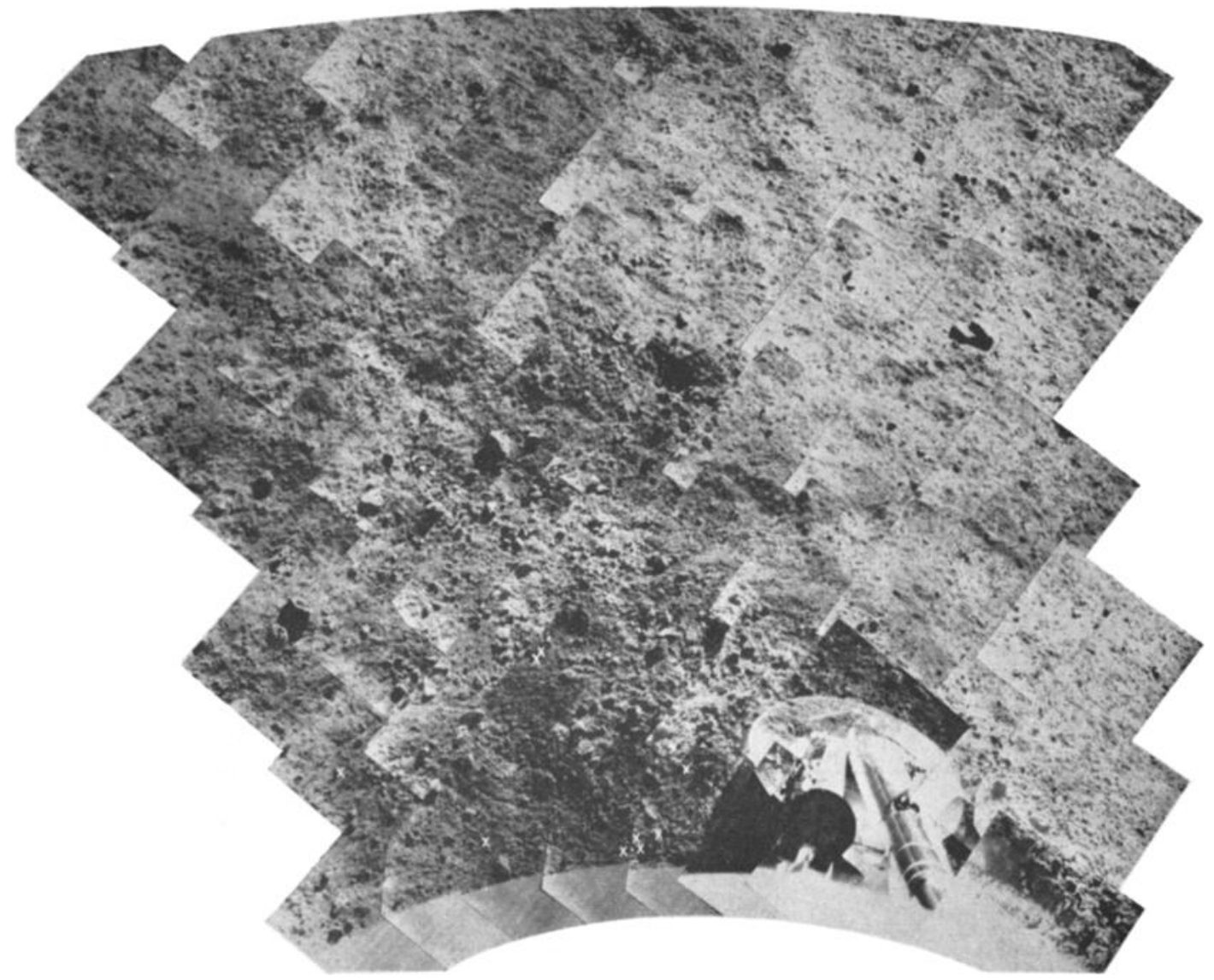

Fig. 16a.

sizes and nozzle heights. Their results showed that, for the nozzle heights where erosion occurred, erosion was more rapid in soils with coarser particles (within limits) than in finegrained soils and that the maximum crater depth was not necessarily directly below the nozzle. Often the resulting crater is in the shape of the lower half of a toroid. Observations show, and theory predicts, that the soil particles leave the surface in a fairly flat trajectory when the surface erosion is small. As the erosion depth increases, the trajectory angle between the particle and the surface increases.

Roberts' [1963] theory was used to estimate the theoretical amount of viscous erosion for a range of soil cohesion for four particle sizes, for the engine conditions listed in Table 1. In these calculations, the aerodynamic friction and drag coefficients acting on the soil particles were taken to be 0.3 and 2, respectively [Roberts, 1964; Hutton, 1966]. The soil internal friction angle was taken to be $35^{\circ}$ [Christensen et al., 1967a]. The results shown in Figure 19 indicate that a soil composed of $100-\mu$ diameter particles with a cohesion of 1430 dynes $/ \mathrm{cm}^{2}$ would erode at a maximum rate of $0.36 \mathrm{~cm} / \mathrm{sec}$. The observed rate is $1.5 \mathrm{~cm} / \mathrm{sec}$; according to Figure 19, this rate could have occurred by viscous action only on a soil composed of particles larger than $500 \mu$. Since most grains present are smaller than $500 \mu$, the comparison of theoretical and observed crater depths suggests that viscous erosion was not the major erosion mechanism for the removal of fine-grained material. Comparison of theoretical and observed crater diameters provides additional evidence. For a soil composed of 600 - $\mu$-diameter particles with a cohesion of 


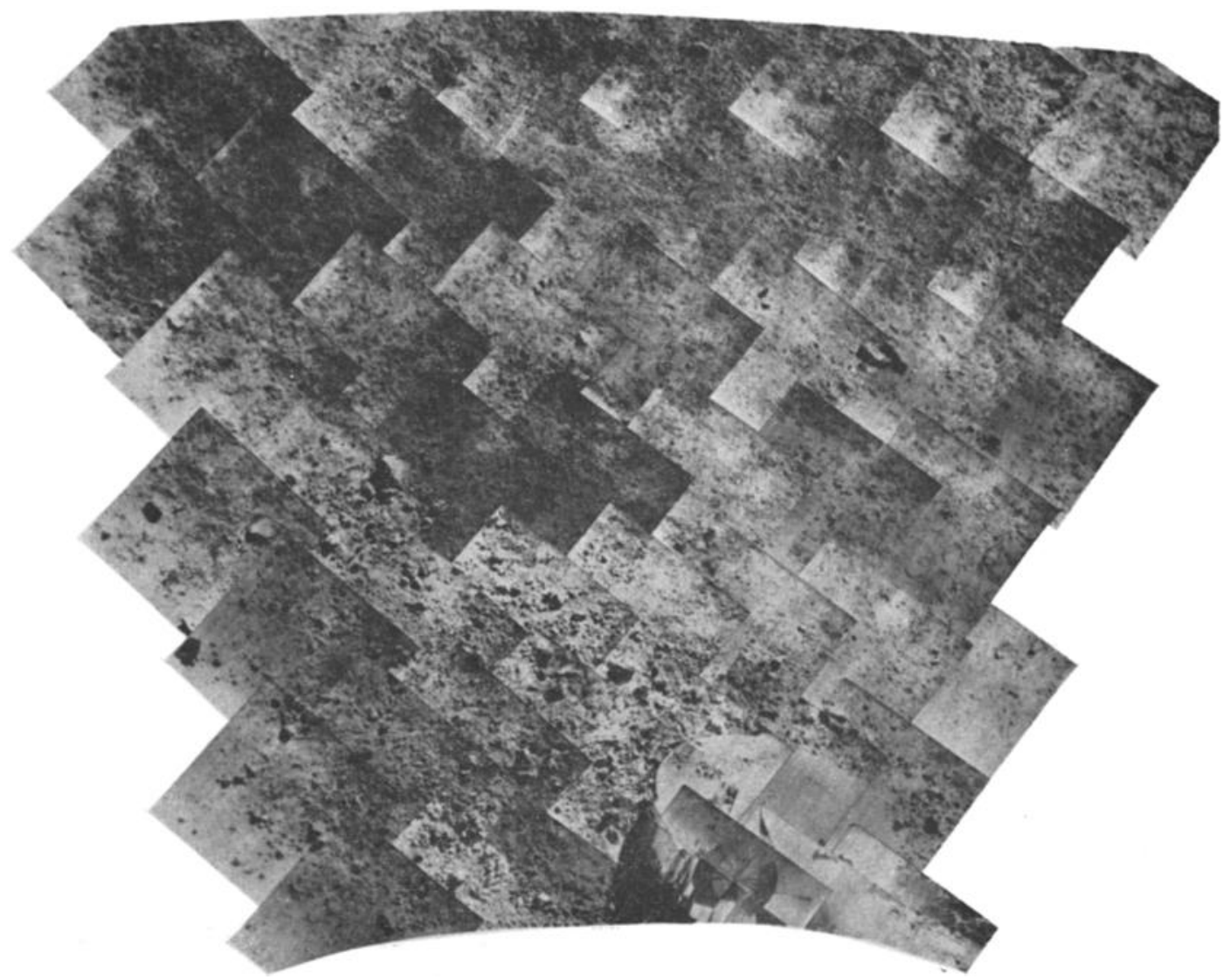

Fig. $16 b$.

Figure 16 shows mosaics of footpad 2 area (a) pre-firing and (b) post-firing. Representative fragments that were moved by the vernier engine firing are marked with an $\mathrm{x}$. Soil on top of the footpad was little disturbed by the firing. (September 12 and 13, 1967; catalog 5-MP-26 and 5-MP-27).

960 dynes $/ \mathrm{cm}^{2}$ (selected to approximate the observed average erosion rate), Roberts' theory gives a crater diameter of $66 \mathrm{~cm}$, whereas the observed crater diameter was about $20 \mathrm{~cm}$.

Thus, viscous erosion was not a major factor in forming the crater. It probably was the mechanism that moved soil fragments across the surface from positions outside the crater.

Diffused gas eruption. During a firing, exhaust gases flow into and through the porous soil, exiting upward at some radial distance and possibly lifting soil from the surface. For soil displacement to occur during this period, the engine must be fired for a time sufficient to achieve a significant upward flow of gases at a distance from the central higher-pressure re- gion. If a crater formed during this period of firing, it would have the shape of half a toroid. On sudden removal of the surface pressure at engine shutdown, some of the gas diffused into the soil during firing will flow to the surface and may produce an eruption. Such a disturbance would occur in the high-pressure region directly under the engine.

The conditions used in the Surveyor 5 static lunar firing test were chosen to emphasize diffused gas erosion at shutdown as the major erosion mechanism. Because the lunar surface loadings developed by exhaust gases from the LM descent engine during landing and by a Surveyor vernier engine firing at low thrust on the moon are similar, it was possible to simulate, 

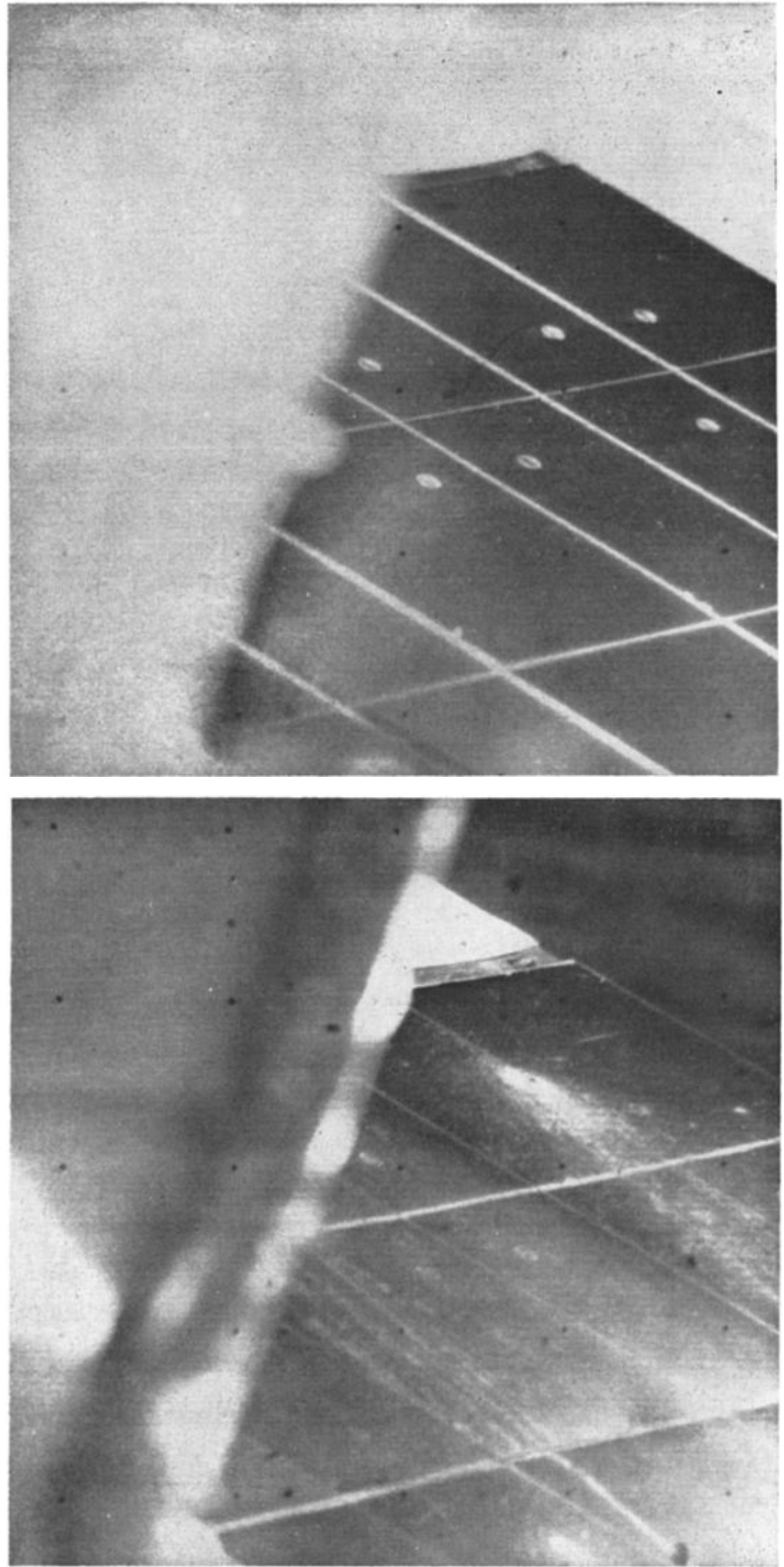

Fig. 17. Top of compartment $B$ taken before and after the firing. A lump of material was transported to the compartment top and splattered in a direction away from vernier engine 1. (Top) September 12, 1967, 02h 29m 29s GMT. (Bottom) September 22, 1967, 05h 48m 58s GMT. 
TABLE 1. Vernier Engine 3 Static-Firing Data [from Christensen et al., 1067b]

\begin{tabular}{|c|c|c|}
\hline Quantity & $\begin{array}{c}\text { Measured } \\
\text { Value }\end{array}$ & $\begin{array}{c}\text { Ysed in } \\
\text { Calculations* }\end{array}$ \\
\hline $\begin{array}{l}\text { Firing time, sec } \\
\text { Thrust, newtons } \\
\text { Chamber pressure, } \\
\text { newtons/cm² } \\
\text { Chamber gas temperature, }{ }^{\circ} \mathrm{K} \\
\text { Chamber gas viscosity, poise } \\
\text { Gas apecific heat } \\
\text { Gas constant, m²/sec }{ }^{\circ} \mathrm{K} \\
\text { Nozzle exit radius, cm } \\
\text { Nozzle exit Mach number } \\
\text { Nozzle height, cm } \\
\text { Angle of nozzle exit plane to } \\
\text { surface below it } \\
\text { Projection of nozzle exhaust } \\
\text { axis, on surface below it } \\
\text { Erosion crater diameter, cm } \\
\text { Erosion crater depth, average, } \\
\text { cm } \\
\text { Erosion crater depth, maxi- } \\
\text { mum, om } \dagger \\
\text { Erosion crater crescent, } \\
\text { direction of cusps }\end{array}$ & $\begin{array}{l}37 \pm 1 \\
0^{\circ}-10^{\circ} \\
\text { Toward } \alpha-8 c \\
20 \\
08 \pm 0.2 \\
13 \\
\text { Toward } \alpha-8 c\end{array}$ & $\begin{array}{l}055 \\
120 \\
469 \\
2950 \\
56 \times 10^{-4} \\
1313 \\
367 \\
6.46 \\
5.2 \\
394 \\
\text { attering head }\end{array}$ \\
\hline
\end{tabular}

\footnotetext{
* Values used in calculations in some cases differ from measured because calculations were made before latest measuremente.

† From Figure 11.
}

in the lunar experiment, the soil erosion effects to be experienced during a LM landing. To simulate the viscous erosion anticipated by LM, a firing time of about 5 sec would have been required for the Surveyor engines at their minimum thrust level. The simulation of the diffused gas eruption phenomenon would require much shorter Surveyor engine firing time, preferably about 0.1 sec. It was apparent, therefore, that both erosion effects would not be simulated with a single vernier engine firing. Indications of the viscous erosion effects were available from the Surveyor 3 second landing event [Christensen et al., 1968]; therefore, it was decided to devote the Surveyor 5 lunar soil erosion test to obtaining the best simulation of engine shutdown eruption effects possible within spacecraft constraints. The 0.55 -sec firing time used was considered the minimum that would ensure predictable performance and provide adequate telemetry of engine performance.

The analysis of diffused gas eruption used the surface pressure obtained from Roberts' theory (Figure 18) for a jet firing normally onto a hori- zontal surface of a homogenous, isotropic, porous medium. The diffusion process is essentially independent of the direction of gravity, and the diffusion-caused soil erosion on a slope of $20^{\circ}$, calculated from the diffusion theory, is hardly distinguishable from that on a horizontal surface. The time for diffusion of gas through the soil to reach a steady state and correspondingly the extent of the soil eruption depend on the soil porosity and permeability. Diffusion theory indicates that the diameter of a diffusion-caused eruption crater is almost independent of the cohesion [Scott and Ko, 1968].

The calculations indicate that a diffused-gas eruption would have formed a crater $32 \mathrm{~cm}$ in diameter and $3.5 \mathrm{~cm}$ deep in a completely cohesionless and very permeable soil (i.e., one

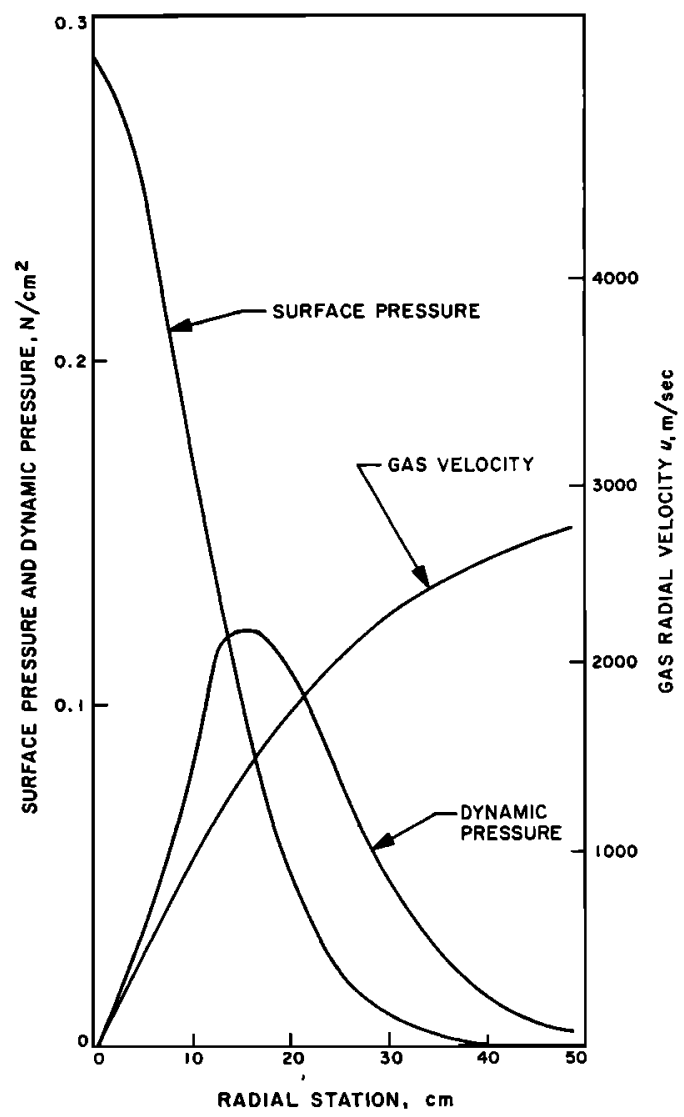

Fig. 18. Theoretical static pressure, dynamic pressure, and exhaust gas radial velocity at the surface of a plane, parallel to the engine nozzle exit plane; engine thrust $=120$ newtons, nozzle height $=39.4 \mathrm{~cm}$. 


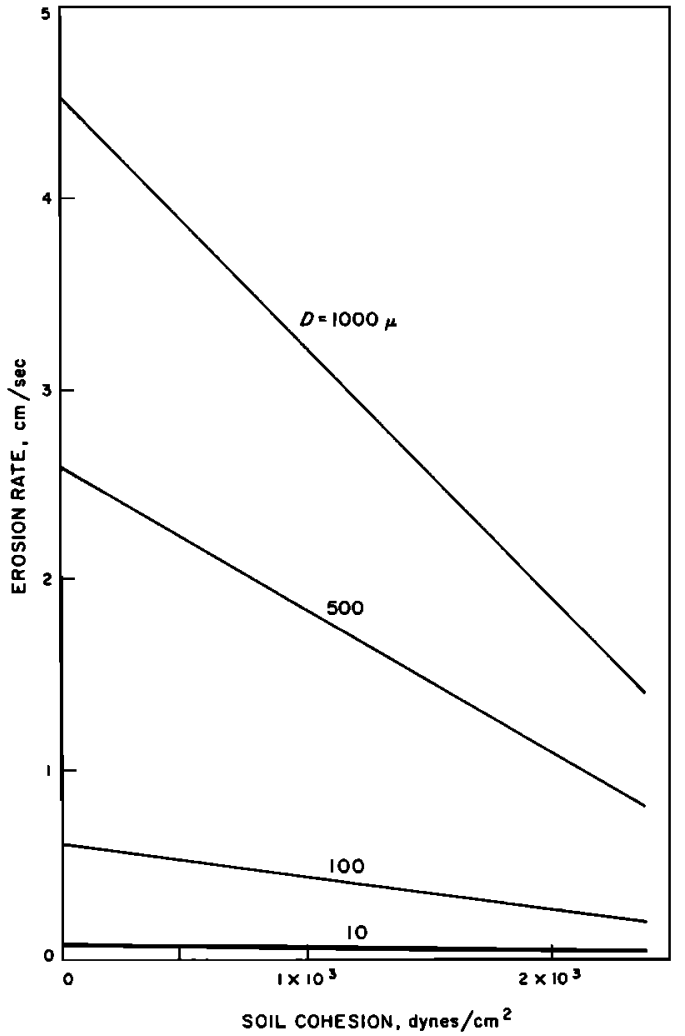

Fig. 19. Theoretical viscous erosion rates as functions of soil cohesion and particle size; engine thrust $=120$ newtons, nozzle height $=39.4 \mathrm{~cm}$.

in which steady-state gas flow conditions were reached by an 0.5 -sec firing), for surface loading conditions corresponding to the Surveyor 5 test. For the same test conditions, but in a cohesionless and less permeable soil (requiring $5 \mathrm{sec}$ to reach steady-state gas flow), however, the eruption crater would have been $18 \mathrm{~cm}$ in diameter and $1.5 \mathrm{~cm}$ deep. If the soil porosity is assumed to be between 0.3 and 0.5 , the viscosity of the vernier exhaust gases in the soil is $1 \times 10^{-4}$ to $3 \times 10^{-4}$ poise $[P a o, 1967]$, and, if it assumed that an 0.5-sec firing is equivalent to about one-tenth the time required to reach steady-state conditions, the soil permeability required to match calculated and observed crater diameters is between $1 \times 10^{-8}$ and $7 \times$ $10^{-8} \mathrm{~cm}^{2}$ [see Scott and $K o, 1968$ ]. The permeabilities of soils of different uniform grain sizes as measured on earth are shown in Figure 20. The permeability range for the lunar surface material fits into the permeability range of silts having grain sizes between 2 and $60 \mu$. The lunar material also contains particles larger than this range and possibly some smaller. However, the estimated lunar permeability indicates most of the particles are in the $2-$ to $60-\mu$ range to a depth of around $25 \mathrm{~cm}$. This estimate agrees with conclusions reached from simulations of Surveyor 3 footpad imprints [Christensen et al., 1968].

The observed crater is attributed to soil removal at engine shutdown, not during firing. If the lunar soil has the permeability indicated, then during an 0.5 -sec Surveyor 5 firing the gases flowing into and through the soil would not have produced diffused-gas eruptions. If the firing time had been increased or the soil permeability were different, so that the eruption did occur before engine shutdown, the resulting crater would have formed at a radius of 19 to $25 \mathrm{~cm}$ from the stagnation point. Since the erosion crater on the moon has only a $10-\mathrm{cm}$ radius, it is concluded that it was formed by diffused-gas eruption at engine shutdown.

The crescent shape of the lunar crater could have been caused by one or several of the following factors:

1. Flow of gases out of the nozzle may not have been symmetric.

2. Material that erupted upward could have settled preferentially on one side because of the surface slope.

3. Lunar soil below the nozzle may have been nonhomogeneous or the surface may have had an irregular shape, and so it was tilted relative to the nozzle exit plane. The direction of the crater cusps is in line with the projection of the exhaust axis on the surface, suggesting that this explanation is likely.

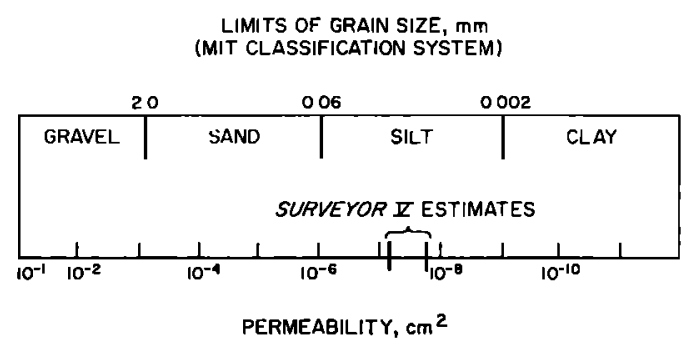

Fig. 20. Permeability of lunar soil compared with permeability of earth soil with various grain sizes. (Earth data from Scott [1963].) 
Movement of $\alpha$-scattering head. An analysis of the forces required to move the $\alpha$-scattering sensor head the observed distance during the time of firing indicates that the effective coefficient of friction between the aluminum skirt of the head and the lunar surface was over 0.59 , and probably over 0.84 ; this includes a contribution from digging of the skirt into the surface. The analysis showed that the coefficient of friction was less than 1.38 [Christensen et al., 1967b].

\section{Conclusions and Summary}

During the lánding, Surveyor 5 slid about 0.8 meter down the inner slope of a $9-\times 12$ meter crater. During this sliding, at least two of the footpads dug trenches in the lunar surface material. The initial depth of penetration for one footpad was about $12 \mathrm{~cm}$. Ejecta was thrown $80 \mathrm{~cm}$ or more.

Soil pressure developed in resisting the footpad sliding during the landing was about 0.9 newton $/ \mathrm{cm}^{2}$, which agrees with the stalling pressure during trenching with the soil mechanics surface sampler on Surveyor 3 .

Best agreement obtained for a compressible soil model with the observed Surveyor 5 footpad penetrations and landing leg loads is for a soil static-bearing capability of 2.7 newtons/ $\mathrm{cm}^{2}$ and a density of $1.1 \mathrm{~g} / \mathrm{cm}^{3}$. Incompressible soil model analyses have not yet been performed for Surveyor 5. Preliminary analyses suggest that soil at the Surveyor 5 landing site is slightly weaker than at previous Surveyor landing sites, or that its resistance to bearing load is reduced by the slope.

Surface material is granular, slightly cohesive, and generally fine-grained, as at the Surveyor 1 and 3 landing sites. The differences in reflectivity between disturbed and undisturbed lunar soil is less than at the Surveyor 1 and 3 landing sites.

During the 0.5 -sec vernier engine firing, soil fragments were moved by viscous erosion from areas below and adjacent to at least one vernier engine. Fragments up to $4.4 \mathrm{~cm}$ in diameter were moved from near the vernier engine, and 0.6-cm fragments were distances up to 1.9 meters. Exhaust gas that had diffused into the soil erupted at engine shutdown, producing a crater $20 \mathrm{~cm}$ in diameter and 0.8 to $1.3 \mathrm{~cm}$ deep under one engine.
Permeability of this lunar soil, to a depth of about $25 \mathrm{~cm}$, is $1 \times 10^{-8}$ to $7 \times 10^{-8} \mathrm{~cm}^{2}$. This corresponds to the permeability of earth silts and indicates most of the lunar particles are in 2 - to $60-\mu$ size range.

Capability of lunar material to adhere to a smooth vertical surface is indicated by the change of reflectivity of the $\alpha$-scattering sensor head as a result of the vernier engine firing.

Vernier engine firing did not cause any degradation in the functional capability of the spacecraft.

Acknowledgments. We thank Frank Sperling, JPL, for his major contributions to the section on spacecraft landing analysis and dynamic simulations; Charles Goldsmith, William Peer, Alex Irving, Albert Plescia, and Lloyd Starkes, JPL, for their work on spacecraft shadow predictions and assembly of photographic mosaics; Robert Breshears, John Stocky, and Charles Dodge, for their vernier engine performance analyses; and Dave Conaway, Margaret Dove, and John Hinchey, Hughes Aircraft Company, for assisting in the landing dynamic simulations.

\section{REFERENCES}

Alexander, J. D., W. Roberds, and R. F. Scott, Soil erosion by landing rockets, Final Report to NASA Manned Spacecraft Center, Houston, Contract NAS9-4825, Hayes International Co., Birmingham, Alabama, 1966.

Christensen, E. M., S. A. Batterson, H. E. Benson, C. E. Chandler, R. H. Jones, R. F. Scott, E. N. Shipley, F. B. Sperling, and G. H. Sutton, Lunar surface mechanical properties-Surveyor 1, $J$. Geophys. Res., 72, 801-813, 1967a.

Christensen, E. M., S. A. Batterson, H. E. Benson, R. Choate, R. E. Hutton, L. D. Jaffe, R. H. Jones, H. Y. Ko, F. N. Schmidt, R. F. Scott, R. L. Spencer, and G. H. Sutton, Lunar surface mechanical properties, in Surveyor 5 Mission Report, Part 2, Science Results, Jet Propulsion Lab. Tech. Rept. 82-1246, 1967b. (Also in Surveyor 5, A Preliminary Report, NASA SP-163, Washington, D. C.)

Christensen, E. M., S. A. Batterson, H. E. Benson, R. Choate, L. D. Jaffe, R. H. Jones, H. Y. Ko, R. L. Spencer, F. B. Sperling, and G. H Sutton. Lunar surface mechanical properties, $J$ Geophys. Res., 73, 4081-4094, 1968.

Deitrick, R. F., C. D. Conaway, L. W. Gammell, and R. H. Jones, Structures and mechanical environment, in Surveyor 1 Flight Performance Final Report, SSD 68223R, vol. 3, section 5.11.2, Hughes Aircraft Co., El Segundo, California, 1966 .

Dodge, C. H., Space exploration programs and space sciences, Space Programs Summary 37-40, vol. 6, pp. 11-15, Jet Propulsion Laboratory, 
California Institute of Technology, Pasadena, California, July 1960.

Hutton, R. E., Investigation of soil erosion and its potential hazard to LM lunar landing, TRW Systems, Eng. Mechanics Rept. 16-11, Redondo Beach, California, 1966.

Land, N. S., and L. V. Clark, Experimental investigation of jet impingement on surfaces of fine particles in a vacuum environment, NASA TND-2683, NASA Langley Research Center, Hampton, Virginia, 1965.

Pao, R. H. F., Fluid Dynamics, C. E. Merrill, Columbus, Ohio, 1967.

Roberts, L., The action of a hypersunic jet on a dust layer, paper presented at the IAS 31st annual meeting, New York, January 21-23, 1963.

Roberts, L., Interaction of a rocket exhaust with the lunar surface, paper presented to meeting on fluid dynamic aspects of space flight, Fluid Dynamics Panel, Advisory Group for Aeronautical Research and Development, Marseilles, France, April 20-24, 1964.

Scott, R. F., Principles of Soil Mechanics, AddisonWesley, Reading, Mass., 1963.

Scott, R. F., and H. Y. Ko, Transient rocketengine gas flow in soils, AIAA J., 6, 258-264, 1968.

Scott, R. F., and F. I. Roberson, Soil mechanics surface sampler: Lunar tests and analysis, $J$. Geophys. Res., 79, 4045-4080, 1968.

(Received March 28, 1968; revised July 15,1968 .) 